\title{
Modeling acoustic propagation of airgun array pulses recorded on tagged sperm whales (Physeter macrocephalus) ${ }^{\text {a) }}$
}

\author{
Stacy L. DeRuiter ${ }^{b)}$ and Peter L. Tyack \\ Biology Department, Woods Hole Oceanographic Institution, Woods Hole, Massachusetts 02543 \\ Ying-Tsong Lin, Arthur E. Newhall, and James F. Lynch \\ Department of Applied Ocean Physics and Engineering, Woods Hole Oceanographic Institution, \\ Woods Hole, Massachusetts 02543
}

Patrick J. O. Miller

Sea Mammal Research Unit, University of St. Andrews, Fife KY16 8LB, Scotland

(Received 26 January 2006; revised 1 September 2006; accepted 13 September 2006)

\begin{abstract}
In 2002 and 2003, tagged sperm whales (Physeter macrocephalus) were experimentally exposed to airgun pulses in the Gulf of Mexico, with the tags providing acoustic recordings at measured ranges and depths. Ray trace and parabolic equation (PE) models provided information about sound propagation paths and accurately predicted time of arrival differences between multipath arrivals. With adequate environmental information, a broadband acoustic PE model predicted the relative levels of multipath arrivals recorded on the tagged whales. However, lack of array source signature data limited modeling of absolute received levels. Airguns produce energy primarily below $250 \mathrm{~Hz}$, with spectrum levels about $20-40 \mathrm{~dB}$ lower at $1 \mathrm{kHz}$. Some arrivals recorded near the surface in 2002 had energy predominantly above $500 \mathrm{~Hz}$; a surface duct in the 2002 sound speed profile helps explain this effect, and the beampattern of the source array also indicates an increased proportion of high-frequency sound at near-horizontal launch angles. These findings indicate that airguns sometimes expose animals to measurable sound energy above $250 \mathrm{~Hz}$, and demonstrate the influences of source and environmental parameters on characteristics of received airgun pulses. The study also illustrates that on-axis source levels and simple geometric spreading inadequately describe airgun pulse propagation and the extent of exposure zones. (c) 2006 Acoustical Society of America. [DOI: 10.1121/1.2359705]
\end{abstract}

PACS number(s): 43.80.Nd, 43.20.Mv, 43.30.Dr [WWA] Pages: 4100-4114

\section{INTRODUCTION}

Airgun arrays are often used as sources of lowfrequency underwater sound for geophysical research and exploration, especially by the oil industry. Airguns generate sound by rapidly releasing compressed air from an airgun cylinder, creating an oscillating air bubble that acts as a source of loud, broadband impulsive sound. The oscillating air bubble also produces a sequence of exponentially decaying bubble pulses following the initial pulse (Parkes and Hatton, 1986). Airguns are generally deployed as horizontal planar towed arrays, minimizing the bubble pulses and directing the main beam of low-frequency sound toward the seafloor (Parkes and Hatton, 1986). Airgun arrays are reported to have theoretical on-axis (directly downward) signatures with peak energy in the 10-200 Hz range, and far-field measure-

\footnotetext{
${ }^{a)}$ Portions of this work were presented in "Preliminary modeling of Dtag acoustic arrivals from the Gulf of Mexico in 2002 and 2003," Proceedings of the Twenty-Third Gulf of Mexico Information Transfer Meeting, U.S. Department of the Interior Minerals Management Service, Gulf of Mexico OCS Region, 2005, and "Quantification and Acoustic Propagation Modeling of Airgun Noise Recorded on Dtag-tagged Sperm Whales in the Gulf of Mexico," Proceedings of the 16th Biennial Conference on the Biology of Marine Mammals, San Diego, CA, December 2005.

b) Author to whom correspondence should be addressed. Electronic mail: sderuiter@whoi.edu
}

ments yield typical peak-to-peak source levels in the range 222-261 dB re $1 \mu \mathrm{Pa}$ when corrected to a source range of $1 \mathrm{~m}$, treating the full array as a point source (Richardson et al., 1995). During seismic surveys, a streamer of hydrophones is also generally towed to record sound reflected from below the seafloor, and characteristics of these reflections are used to invert for bottom properties and map subseafloor features (Barger and Hamblen, 1980; Caldwell and Dragoset, 2000; Dragoset, 2000; Richardson et al., 1995). Although much of the acoustic energy produced by an airgun array is in the frequency range below $250 \mathrm{~Hz}$, both field recordings and models of source spectra illustrate that airguns can produce significant energy at frequencies up to at least $1 \mathrm{kHz}$ [source energy at $1 \mathrm{kHz}$ is about $40 \mathrm{~dB}$ re $1 \mu \mathrm{Pa}^{2} / \mathrm{Hz}$ less than at $50 \mathrm{~Hz}$ (Blackman et al., 2004; Caldwell and Dragoset, 2000; Goold and Fish, 1998)]. Due to their high source levels and their low frequency content, airgun array transmissions in suitable ocean environments have been detected above background noise at distances of up to $3000 \mathrm{~km}$ (Nieukirk et al., 2004).

The source level and frequency range of airgun pulses have generated concern that they may adversely affect fish and marine mammals. Airgun noise could produce adverse effects by direct injury, for example by damaging the animals' ears, or by less direct mechanisms, such as by masking 
sounds or disrupting behavior. In terms of wildlife conservation, the primary concern regarding these alterations involves questions about whether they could affect populations by reducing survival, reproductive success, or foraging effectiveness. Experiments have documented that exposure to airgun pulses at close range can damage fish ears (McCauley et al., 2003), that fish catches are reduced during airgun surveys in an area (Engås et al., 1996), and that some marine mammals may change their behavior in response to airgun exposure (Engås et al., 1996; McCauley et al., 2003; Richardson et al., 1995).

One method for determining whether, and how, airgun transmissions might affect marine mammals involves controlled exposure experiments (CEEs), in which animals are observed pre-exposure and then exposed to a controlled level of sound. A set of CEEs to measure the response of sperm whales to airgun sounds took place during the Sperm Whale Seismic Study (SWSS) in the Gulf of Mexico during September 2002 and June 2003 (Jochens and Biggs, 2003, 2004). During the experiments, sperm whales were tagged with a Dtag, an archival tag that records acoustic, depth, and orientation information (Johnson and Tyack, 2003). Tagged whales were exposed to airgun array transmissions at ranges from 1 to $13 \mathrm{~km}$. The tags recorded whale movements and vocalizations during the exposure as well as airgun sound arrivals at a variety of source-whale ranges and whale depths. Analysis of the effects of airgun exposure on sperm whale foraging behavior in the Gulf of Mexico and determination of airgun received levels at the whales during these two studies will be presented in two other papers [Miller et al. (unpublished) and Madsen et al. (2006)]. In this paper, we study the acoustic propagation of airgun signals recorded on Dtags with standard acoustic propagation models. We show that seasonally and spatially variable environmental characteristics play critical roles in determining spectra and levels of airgun arrivals at the whales. Our results also show how source directivity and a surface ducting effect may proportionally increase the high-frequency content of airgun signals arriving at whales near the surface compared to on-axis airgun spectra.

To put the discussion of our modeling techniques and results in context, we have structured this article as follows. Before addressing the CEEs of the Sperm Whale Seismic Study (SWSS) in the Gulf of Mexico, we will begin by discussing the sound sources and receivers employed during the experiments and the acoustic environment in which the CEEs took place. We reiterate that there were two components to the experiment, one that took place in September 2002 and one in June 2003, and we outline differences and similarities between the 2 years. Next, we describe the field experimental techniques and the acoustic models used to analyze the data. We then present the modeling results for each year. Finally, we discuss the implications and significance of our work, emphasizing that near-surface receivers may detect significant sound energy above $250 \mathrm{~Hz}$ in certain conditions and that geometric spreading approximations, which have traditionally been used to determine the extent of marine animal exposure zones, are inadequate to describe transmission loss in our study environments.



FIG. 1. Configuration of the M/V Speculator airgun array, used in the 2002 experiment. Numbers inside individual airguns indicate the displacement (in cubic inches) of each gun.

\section{ACOUSTIC SOURCES, RECEIVERS, AND ENVIRONMENT}

\section{A. Sound sources: Airgun arrays}

In 2002, tagging operations were based on the R/V Gyre, and the airgun source vessel was the M/V Speculator (the coastal vessel Speculator was mounted aboard the deepwater service vessel $\mathrm{M} / \mathrm{V}$ Rylan $T$ to allow work in deepwater research areas). The Speculator airgun array was a tuned array $8 \mathrm{~m}$ long and $6 \mathrm{~m}$ wide, including 20 external sleeve type airguns of various volumes for a total volume of $1680 \mathrm{in}^{3}$. Figure 1 shows the configuration of the Speculator array. During CEEs, the airgun array was towed at a nominal depth of $6 \mathrm{~m}$ and fired every $15 \mathrm{~s}$, with a ramp-up at the start of each firing period during which the number of airguns fired was gradually increased. In this study, we analyzed only recordings of full-array airgun arrivals. The equivalent pointsource source level of the array, backcalculated from the onaxis (directly downwards) theoretical far-field signature [shown in Fig. 2(a)], was reported to be $258 \mathrm{~dB}$ re $1 \mu \mathrm{Pa} @ 1 \mathrm{~m}$ (peak-peak) in the 3-800 Hz frequency band (Jochens and Biggs, 2003). Frequency notches in the spectrum of the theoretical far-field signature, which is shown in Fig. 2(b), indicate a Lloyd's mirror effect.

Because sound from an airgun array will reflect at the ocean surface (which is approximately a pressure-release boundary), a Lloyd's mirror effect will occur, and airgun pulse arrivals at distant (far-field) receivers will include, in addition to the direct arrival, a 180-degree-phase-shifted, surface-reflected arrival (Frisk, 1994). This reflected arrival is equivalent to the sound that would be received from a virtual mirror image source located above the sea surface, with approximately the same source amplitude as the airgun array but with opposite polarity [the exact mirror source amplitude depends on sea-surface roughness and source frequency (Jovanovich et al., 1983)]. Interference between the direct pulse and the surface reflection affects the time and frequency structure of pulses recorded at distant receivers, lengthening the pulse and introducing frequency nulls into the source spectrum (Caldwell and Dragoset, 2000; Parkes and Hatton, 1986). The effect varies with airgun array tow depth: as tow depth increases, frequency nulls occur at more 

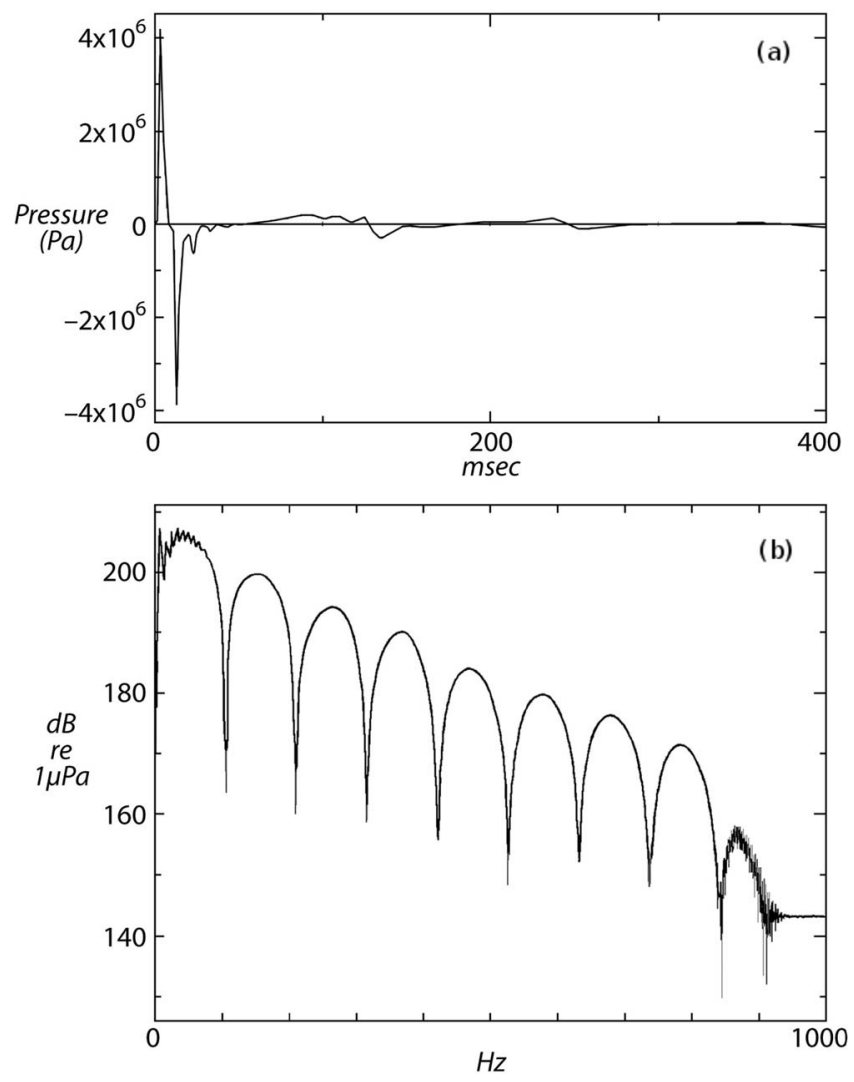

FIG. 2. (a) On-axis theoretical source signature of the M/V Speculator airgun array and (b) its amplitude spectrum. Both plots are extracted from Jochens and Biggs (2003).

closely spaced intervals in the source spectrum, and source pressure amplitude increases at frequencies below $100 \mathrm{~Hz}$ (Parkes and Hatton, 1986).

The beampattern of a planar array composed of identical point sources has grating lobes when the spacing between array elements, $d$, is greater than $\lambda / 2$ (where $\lambda$ is source wavelength). The grating lobes are centered at angles $\theta$ from the acoustic axis such that $n \lambda=d \sin (\theta)$ (where $n$ $=1,2,3, \ldots)$ (Tipler and Llewellyn, 2003). For the Speculator array, the spacing between airgun clusters was about $3 \mathrm{~m}$ in the $x$ dimension (along the bow-stern axis of the source vessel) and about $6 \mathrm{~m}$ in the $y$ dimension (perpendicular to the bow-stern axis of the source vessel). Therefore, the array beampattern should have grating lobes for source frequencies above approximately $250 \mathrm{~Hz}$ in the $x-z$ plane and approximately $125 \mathrm{~Hz}$ in the $y-z$ plane (assuming a sound speed of $1500 \mathrm{~m} / \mathrm{s}$ ), although array shading will affect the pattern of grating lobes somewhat (Urick, 1975). The presence of grating lobes in the array beampattern at higher frequencies increases the proportion (but not the absolute amount) of higher-frequency energy transmitted by the array at launch angles close to parallel to the sea surface. Detailed modeling of the Speculator array beampattern will be presented later in the paper, and will include the Lloyd's mirror effect from sea-surface reflection as well as the effects of array geometry mentioned here.

The Fresnel zone or near field of an acoustic array extends to a range of about $D^{2} / \lambda$, where $D$ is the array dimen-

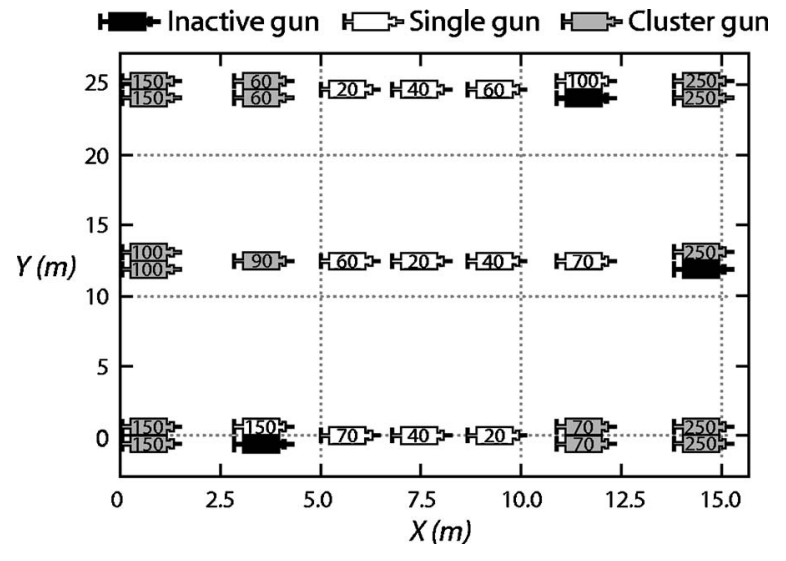

FIG. 3. Configuration of the M/V Kondor airgun array, used in 2003 experiment. Numbers inside individual airguns indicate the displacement (in cubic inches) of each gun.

sion (length or width) and $\lambda$ is sound wavelength (Clay and Medwin, 1977). Assuming a sound speed of $1500 \mathrm{~m} / \mathrm{s}$, the far field of the Speculator array begins about $2 \mathrm{~m}$ from the source at $50 \mathrm{~Hz}$ and about $85 \mathrm{~m}$ from the source at $2 \mathrm{kHz}$. All airgun pulses used in this study were recorded in the far field.

In 2003, tagging operations and visual and acoustic monitoring were based on the R/V Maurice Ewing, and the airgun source vessel was the M/V Kondor Explorer. The Kondor array was a tuned array, $15 \mathrm{~m}$ long and $10 \mathrm{~m}$ wide, with 31 guns of various sizes for a total volume of $3090 \mathrm{in}^{3}$. Only 28 of the guns were active during the experiment, making the total volume of the active guns $2590 \mathrm{in}^{3}$. Figure 3 shows the configuration of the array. The private geoservice firm PGS Exploration (Walton-on-Thames, Surrey, UK) provided the on-axis theoretical far-field signature of the array (shown in Fig. 4). Backcalculating from the signature, the equivalent point-source source level was $261 \mathrm{~dB}$ re $1 \mu \mathrm{Pa} @ 1 \mathrm{~m}$ (peak-peak) in the 3-218 Hz frequency band. During CEEs, the airgun array was towed at a nominal depth of $7.5 \mathrm{~m}$ and fired every $15 \mathrm{~s}$, with a ramp-up at the start of each firing period during which the number of guns fired was gradually increased to 28 . In this study, we analyzed only recordings of full-array airgun arrivals. Like the Speculator array, the Kondor array source signature is also affected by a Lloyd's mirror effect. The Kondor array beampattern should also have grating lobes for source frequencies above approximately $375 \mathrm{~Hz}$ in the $x-z$ plane and approximately $75 \mathrm{~Hz}$ in the $y-z$ plane (calculated as explained earlier for the Speculator array, only using airgun cluster spacings of $2 \mathrm{~m}$ in the $x$ dimension and $10 \mathrm{~m}$ in the $y$ dimension), again increasing the proportion of higher-frequency energy transmitted by the array at launch angles close to parallel to the sea surface. The Fresnel near field of the Kondor array begins at about $8 \mathrm{~m}$ from the array at $50 \mathrm{~Hz}$ and $300 \mathrm{~m}$ from the array at $2 \mathrm{kHz}$ (calculated as above for the Speculator array). Again, all airgun pulses used in this study were recorded in the far field.

\section{B. Receivers: Dtags}

Sperm whales (Physeter macrocephalus) were tagged with Dtags, digital archival tags that record acoustic, depth, 

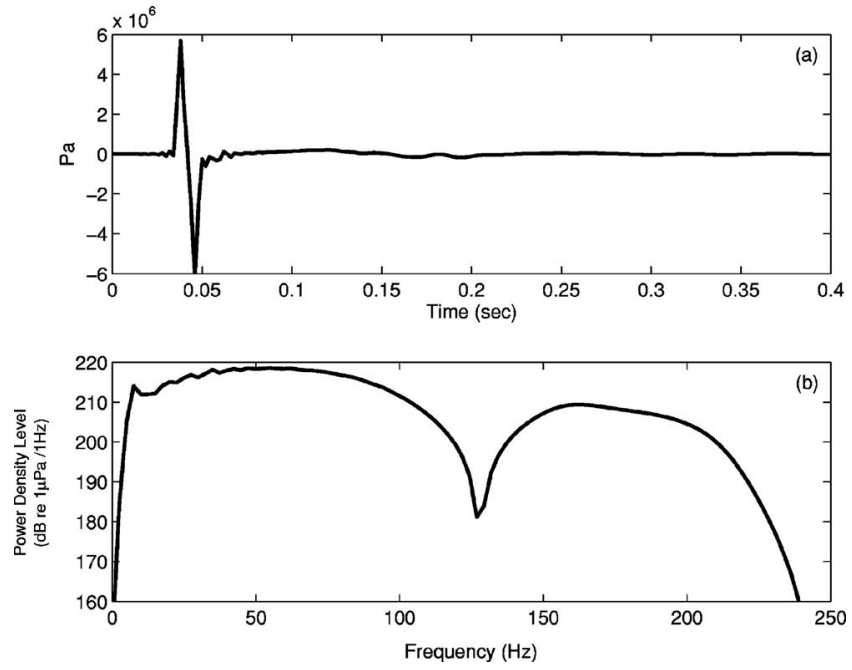

FIG. 4. (a) On-axis theoretical source signature of the M/V Kondor airgun array and (b) its amplitude spectrum $(0-250 \mathrm{~Hz})$. Both plots were provided by PGS Exploration (Walton-on-Thames, Surrey, UK).

and animal orientation data (Johnson and Tyack, 2003). Orientation data recorded by the tag can be combined with visual tracks to derive an estimate of the position of the tagged whale (Zimmer et al. 2005). Two versions of the Dtag were used in the experiments. In 2002, Dtagl tags were used. Dtagl recorded audio at a sampling rate of $32 \mathrm{kHz}(12$ bit resolution), with flat frequency response $( \pm 3 \mathrm{~dB})$ between $400 \mathrm{~Hz}$ and $10 \mathrm{kHz}$ and clip level of $155 \mathrm{~dB}$ re $1 \mu \mathrm{Pa}(0-$ peak). Filtering was applied to postemphasize the audio recordings at low frequencies. With postemphasis, the frequency response was flat $( \pm 1.5 \mathrm{~dB})$ from $60 \mathrm{~Hz}$ to $12 \mathrm{kHz}$. Dtagl also recorded data from three-axis accelerometers and magnetometers, ambient pressure (depth), and temperature at a sampling rate of $48 \mathrm{~Hz}$. In 2003, both Dtagl and Dtag2 tags were used, but only Dtag2 data were analyzed in this study. Dtag2 recorded audio at a sampling rate of $96 \mathrm{kHz}$ (16 bit resolution), with flat $( \pm 1.5 \mathrm{~dB})$ frequency response between $400 \mathrm{~Hz}$ and $45 \mathrm{kHz}$ and clip level of $193 \mathrm{~dB}$ re $1 \mu \mathrm{Pa}(0-$ peak). Filtering was applied to postemphasize the audio recordings at low frequencies. With postemphasis, the frequency response was flat $( \pm 1.5 \mathrm{~dB})$ from $50 \mathrm{~Hz}$ to $45 \mathrm{kHz}$. Dtag2 also recorded data from three-axis accelerometers and magnetometers, ambient pressure (depth), and temperature at $50 \mathrm{~Hz}$. Figure 5 shows the sensitivity curves of Dtagl and Dtag2. Both Dtagl and Dtag2 measured temperature near the crystal used to control clock speed of the tag. Their thermistors did not measure ambient water temperature.

\section{Ocean and ocean acoustic environment}

The CEE components of the SWSS in the Gulf of Mexico were performed in September 2002 and July 2003, and we analyzed data from one exposed whale per year. Figure 6 shows the study areas where the data modeled in this study were collected. On September 11, 2002, the modeled CEE took place on a bathymetric slope of about $1.5^{\circ}$ in the west Mississippi Canyon region, in an area where the water depth varies from 400 to $800 \mathrm{~m}$. On June 13, 2003, the mod-

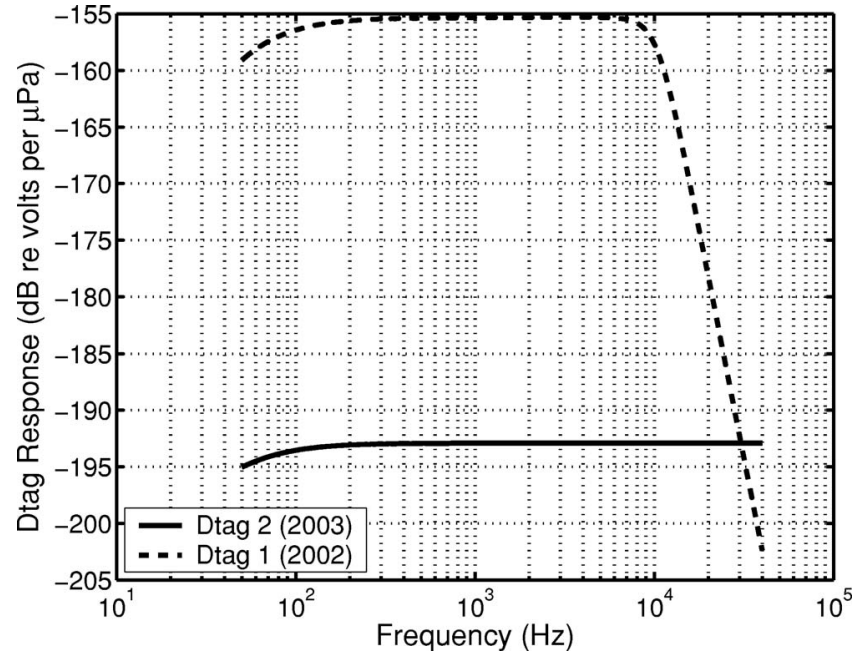

FIG. 5. Frequency response of acoustic sampling of Dtags 1 and 2.

eled CEE took place in the Mississippi Canyon, in an area where the bathymetry is locally flat and the water depth is about $800 \mathrm{~m}$.

During the CEE cruises in both years, CTD (conductivity, temperature, depth) and XBT (expendable bathythermograph) casts were made periodically to estimate the sound speed profile (Jochens and Biggs, 2003, 2004). For acoustic modeling of 2002 airgun pulses, we chose one XBT profile from the 2002 data set, closest to the experiment site and the airgun exposure time. The profile [Fig. 7(a)] indicates a $40 \mathrm{~m}$ thick mixed layer below the sea surface, which created a strong surface duct that trapped high-frequency sound and allowed it to propagate with little transmission loss (Urick, 1975). All sound speed profiles taken from the CTD and XBT casts in 2002 showed a similar surface duct. For acoustic modeling of 2003 airgun pulses, we averaged data from two CTD profiles taken near the experiment site to obtain our sound speed profile. Unlike the 2002 sound speed profile, the 2003 profile did not include a strong surface duct [Fig. $7(\mathrm{~b})]$.

No bottom surveys were conducted during the CEE cruises, but marine geology and geoacoustic reports near the experiment areas are available to help establish the geoacoustic bottom model. According to the NGDC Seafloor Surficial Sediment (Deck41) Database (http:// www.ngdc.noaa.gov), the dominant lithological component of the surficial seafloor in the CEE areas is clay, and the secondary lithological component is silt. The ratio of bottom sound speed to water sound speed at the seafloor should be about 0.995 , a typical value for silty-clay sediments (Hamilton, 1980).

A chirp sonar subbottom survey during the Littoral Acoustic Demonstration Center experiment in August 2001 (Turgut et al., 2002) was conducted in the same area as the 2002 modeled CEE, and sound speed and density profiles from that report are reproduced in Fig. 8(a). Comparing the ocean bottom sound speed to the water sound speed, as shown in Fig. 7(a), confirms that the sound speed ratio at the 2002 study site matches the ratio typical of silty-clay sedi- 

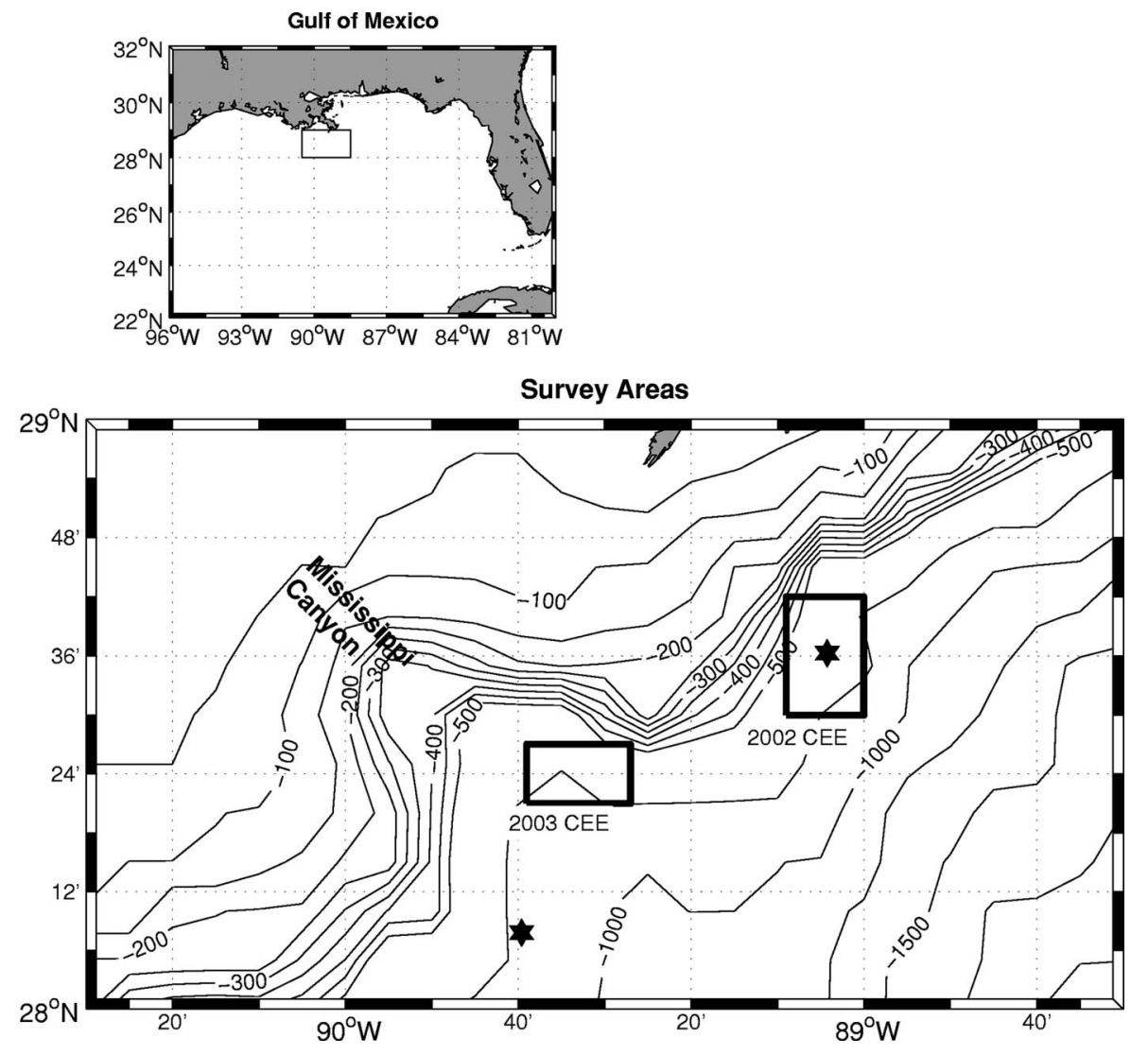

FIG. 6. Sites of airgun operations measured in 2002 and 2003. Upper panel: Location of the study areas. Lower panel: Detail of the 2002 and 2003 study sites (boxes) and locations where data on bottom properties were collected by Turgut $e t$ al. (2002) and Geresi et al. (2005) (stars).

ments. Figure 8(b) shows reflection coefficient versus grazing angle on the seafloor at the site of the 2002 modeled CEE, calculated with the acoustic modeling package OASES (Schmidt, 2004) using data on bottom properties from Turgut et al. (2002). For acoustic modeling of the $2002 \mathrm{CEE}$, we adopted a smoothed version of Turgut's seafloor sound speed and density profiles.

We did not find data on the bottom properties at the site of the 2003 modeled CEE in the literature; the closest detailed studies of the sea floor were conducted in 2003 on Mississippi Canyon Block 798 (about $20 \mathrm{~km}$ from the 2003 CEE site, but on the opposite side of the canyon; see Fig. 6)
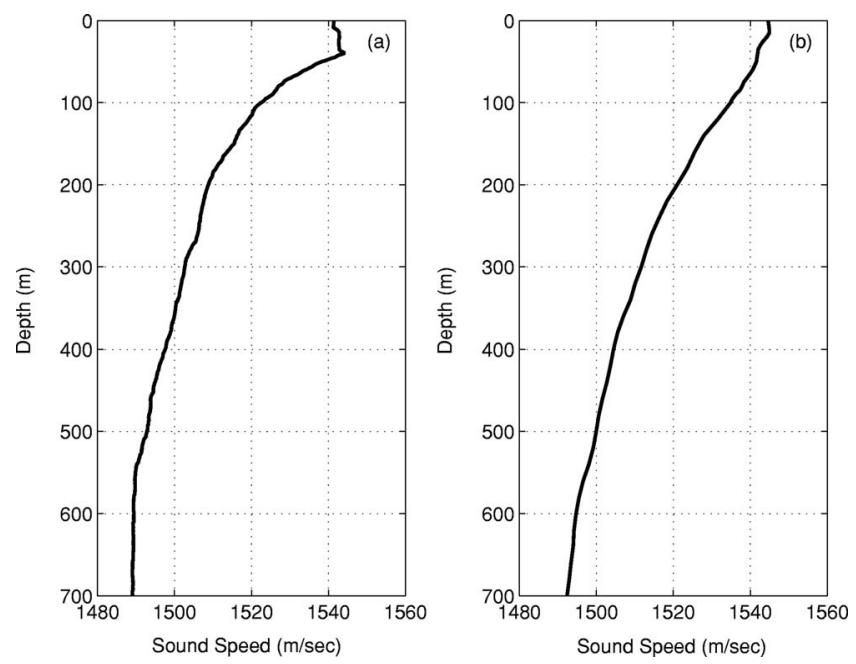

FIG. 7. Sound speed profiles for 2002 (left) and 2003 (right) used for acoustic modeling.
(McGee et al., 2003). Geresi et al. (2005) applied a migration velocity analysis to McGee and colleagues' seismic reflection data and obtained the bottom sound speed to $600 \mathrm{~m}$ depth, which is reproduced in Fig. 9(a). The sound speed ratio between the top layer of the bottom and deep water [shown in Fig. 7(b)], 0.993, is typical of silty-clay sediments. Figure 9(b) shows the bottom reflection coefficient as a function of frequency and grazing angle on the seafloor at the site of the 2003 modeled CEE, calculated with the acoustic modeling package OASES (Ocean Acoustics and Seismic Exploration Synthesis) (Schmidt, 2004) using bottom properties from Geresi et al. (2005). We used Geresi's seafloor sound speed profiles to model the 2003 CEE data.

We applied Hamilton's regression equations to the selected bottom profiles to estimate the bottom density (Hamilton, 1978) at the 2003 study site and the bottom attenuation (Hamilton, 1972) at both sites.

\section{METHODS}

\section{A. Experiments}

Dtags were deployed by approaching sperm whales at the surface in a small inflatable boat, then using a long pole to place the tag atop a whale's back, where it attached with suction cups. The tags were positively buoyant and programmed to release from the whales after a maximum recording time of $12 \mathrm{~h}$ (Dtagl) or $16 \mathrm{~h}$ (Dtag2), at which point they floated to the surface and were located and recovered with the help of a built-in radio beacon. Since the tags were attached to the whales, it is possible that shadowing by the whales' bodies might have affected recorded airgun pulses. 
(a)
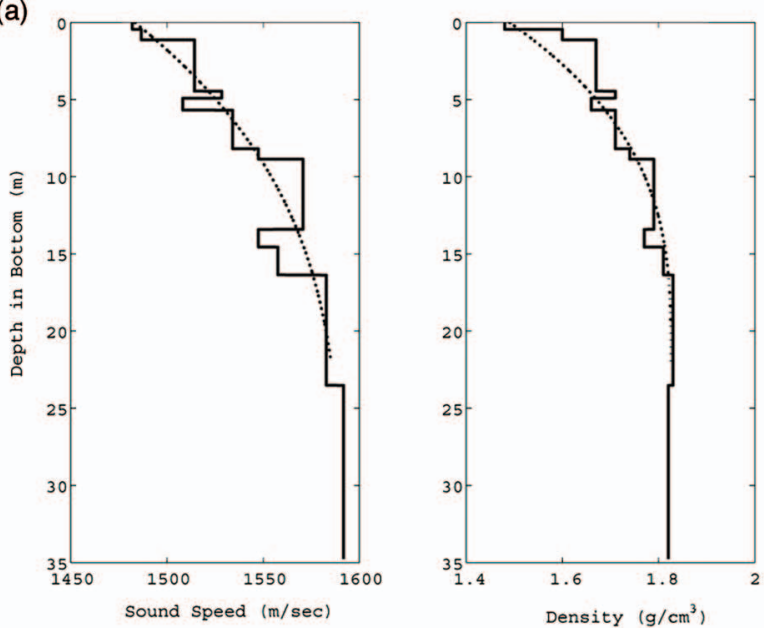

(b)

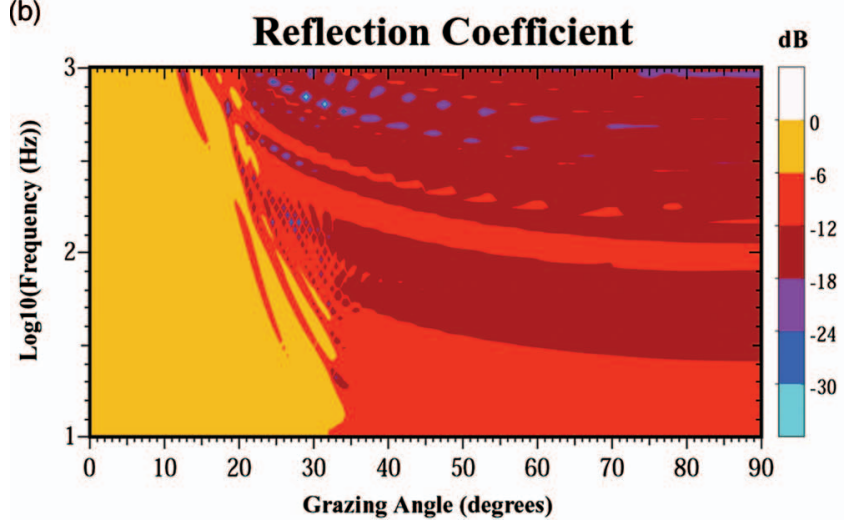

FIG. 8. (a) Bottom sound speed and density profiles for the 2002 study area The solid lines are the geoacoustic inversion results from wideband $(2-12 \mathrm{kHz})$ chirp sonar data obtained from a Littoral Acoustic Demonstration Center experiment on the east of the Mississippi Canyon in 2001 (Turgut et al., 2003). The dotted lines are fitted curves. (b) Corresponding reflection coefficient contour (grazing angle vs frequency) for the 2002 study area. The corresponding density and attenuation profiles were calculated using Hamilton's regression equations (Hamilton, 1972, 1978).

However, body shadowing should have negligible impact on the timing of pulse arrivals, and only minor influence on relative levels at the frequencies we studied. In fact, body shadowing would have a greater effect in reducing high frequencies than low, which would only reduce the surface ducting effect described in this study. In 2002, one whale underwent a CEE on September 10, and three simultaneously tagged whales underwent a CEE on September 11. In 2003, CEEs were performed on individual tagged whales on June 13 and 22, and two simultaneously tagged whales underwent a CEE on June 14. Each CEE lasted about $1 \mathrm{~h}$, and was preceded and followed by tagged control periods with no airgun exposure. Visual observers on the observation vessel tracked the tagged whales using reticle-binoculars and the radio-beacon in the tag. A derived three-dimensional (3D) track for the entire tag attachment period, estimated to be accurate to $\pm 0.5 \mathrm{~km}$, was calculated using dead-reckoning based on the orientation sensors and the visual locations [Johnson and Tyack, 2003; Madsen et al. (2006)]. Horizontal ranges between the airgun arrays and the whales were calculated to the nearest $0.1 \mathrm{~km}$ using the derived tracks.

In this study, we modeled airgun arrivals recorded on (a)
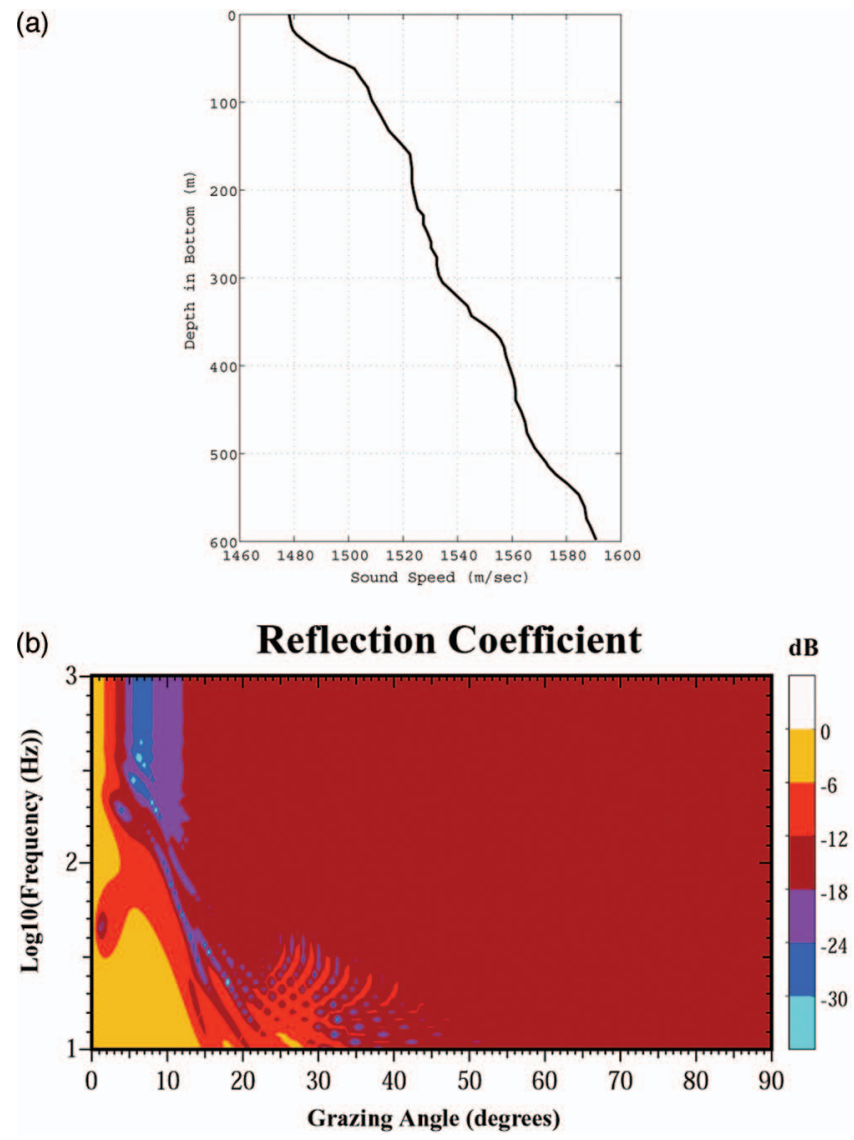

FIG. 9. (a) Bottom sound speed profile for the 2003 study area. The sound speeds were obtained by applying the migration velocity analysis to reflection seismic data on Mississippi Canyon Block 798 (Geresi et al., 2005). (b) Corresponding reflection coefficient contour (grazing angle vs frequency) for the 2003 study area. The corresponding density and attenuation profiles were calculated using Hamilton's regression equations (Hamilton, 1972, 1978).

one tagged whale each year (whale sw02_254b, tagged on September 11, 2002, and whale sw03_164a, tagged on June 13, 2003). Table I presents the exact durations and timing of the tag deployments that included the modeled CEEs. During the 2002 exposure, source-whale range varied from 5.4 to $12.0 \mathrm{~km}$, and water depth varied from 600 to $800 \mathrm{~m}$. During the 2003 exposure, source-whale range varied from 11.0 to $12.0 \mathrm{~km}$, and water depth was about $800 \mathrm{~m}$. Figure 10 shows the locations of the airgun source vessels and tagged whales during the modeled exposures, along with the bathymetry of each study area.

\section{B. Acoustic models}

\section{Normal mode model for determination of the cutoff frequency}

Surface ducts are shallow (generally less than $100 \mathrm{~m}$ deep), so only higher-frequency (shorter-wavelength) sound

TABLE I. Duration and timing of modeled tag deployments and CEEs in 2002 and 2003

\begin{tabular}{llcc}
\hline \hline Date & Whale ID & Tagged time & Airgun exposure time \\
\hline 9/11/2002 & sw02_254b & $10: 28-22: 52$ & $12: 16-14: 20$ \\
6/13/2003 & sw03_164a & $09: 48-23: 20$ & $18: 26-19: 26$ \\
\hline \hline
\end{tabular}



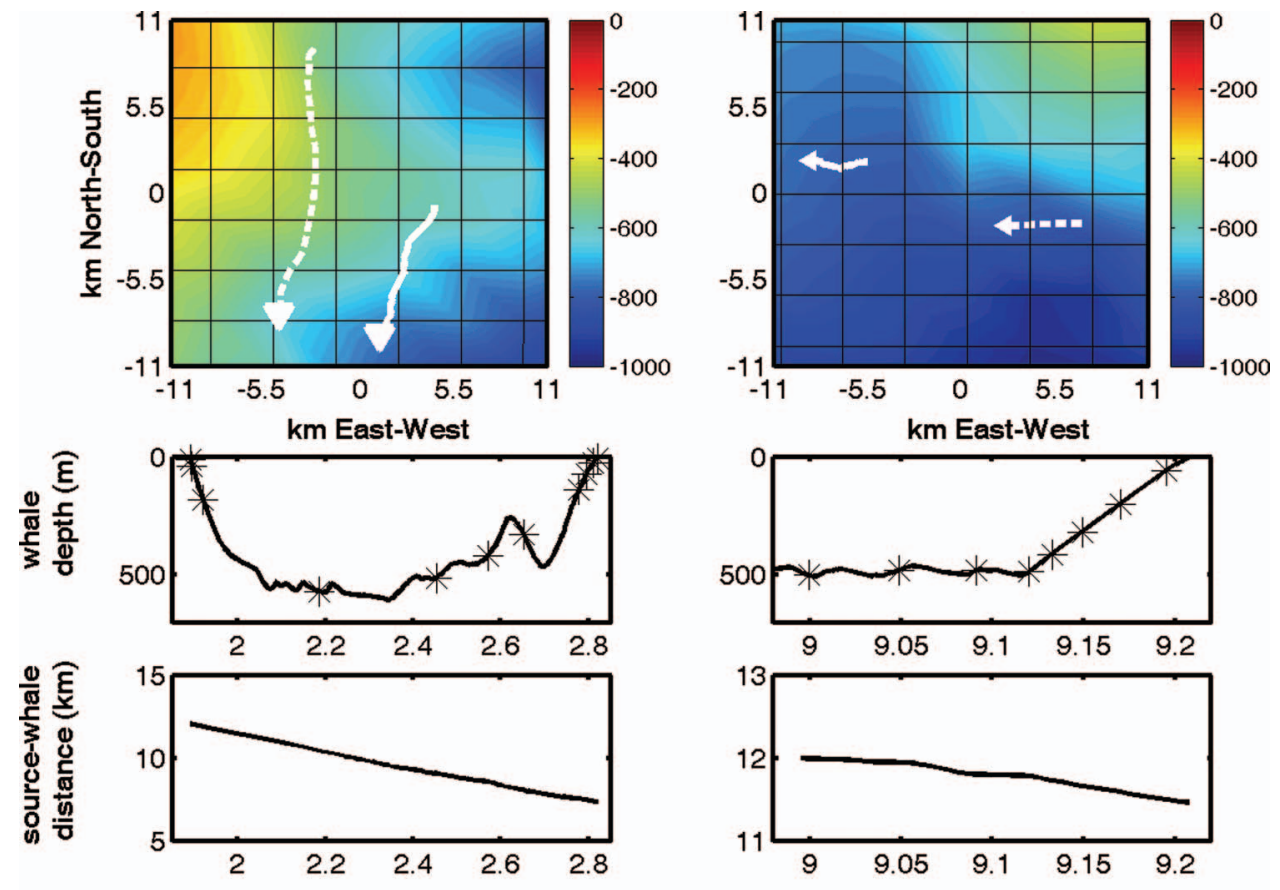

Time since tag attachment (hrs)

FIG. 10. The left column contains information related to the controlled exposure experiment on September 11, 2002, and the right column contains information on the controlled exposure experiment on June 13, 2003. Top panels: Airgun array source vessel (dotted lines) and tagged sperm whale (solid lines) locations during the two modeled airgun exposures. Arrowheads indicate direction of travel. The $x$ and $y$ axis values indicate distance in km from approximate centers of the study locations: $28.600^{\circ} \mathrm{N}, 89.070^{\circ} \mathrm{W}(2002)$ and $28.380^{\circ} \mathrm{N}, 89.520^{\circ} \mathrm{W}$ (2003). Middle panels: Dive profiles of the tagged whales during the modeled exposures. Asterisks indicate the time of firing of modeled airgun pulses. Lower panels: Range from the airgun source vessels to the tagged whales during the modeled exposures.

is trapped and propagates efficiently in surface ducts (Urick, 1975). The cutoff frequency of a surface duct is the approximate frequency below which sound is not trapped in the duct. Cutoff frequency is approximate because sound below the cutoff frequency may be only partially trapped in the duct (a "leaky duct"), and sound may need to be significantly above the cutoff frequency for maximal trapping to occur. To estimate the cutoff frequency of the surface duct in our 2002 study area, we performed a series of KRAKEN normal mode model runs (Porter, 1995) at five frequencies ranging from 50 to $1600 \mathrm{~Hz}$. We used the model output to determine the mode number $n$ and modal eigenvalue $k_{n}$ for the lowestnumbered mode trapped in the duct at each frequency (a mode was considered trapped if it had high intensity in the duct, and exponentially decaying intensity below the duct). Then, to determine whether mode $n$ would propagate, we calculated its mode-propagation cutoff frequency, $\omega_{n}$ (the frequency above which at least $n$ modes will propagate). Trapped modes with $\omega_{n}$ less than the frequency of the KRAKEN model run that generated them would propagate. We estimated $\omega_{n}$ according to Frisk (1994):

$$
\omega_{n}=k_{z n} c,
$$

where

$$
k_{z n}=\sqrt{\left(\frac{\omega}{c}\right)^{2}-k_{n}^{2}},
$$

$\omega$ is radian frequency and $c$ is sound speed. We used $1543 \mathrm{~m} / \mathrm{s}$ for sound speed in the calculations [see Fig. $7(\mathrm{a})]$. This procedure determined whether or not the trapped modes would propagate in the duct at each frequency tested, and therefore allowed us to estimate the cutoff frequency of the surface duct as the lowest frequency at which the trapped modes would propagate.

\section{Airgun array beampattern model}

An airgun array usually contains airgun elements with different volumes, which produce sound pulses with different amplitudes, damping rates and bubble pulse periods ( $\mathrm{Zi}$ olkowski, 1970). This variability makes airgun array signature modeling complex and difficult. One can estimate the signature from near-field measurements of an airgun array (Ziolkowski et al., 1982, 1997; Laws et al., 1998), but during the CEEs we studied, no near-field measurements of airgun pulses were made. An alternative way to estimate the signature of an airgun array is to treat each element as a monopole source and consider the geometric configuration of the array. The volume of every element in the Speculator and Kondor arrays was known, and since the amplitude of an airgun element is approximately proportional to the cube-root of its volume, we could estimate the relative amplitude of the elements in each array (Caldwell and Dragoset, 2000). We modeled the array according to the following normalized formulation in a free space bounded by the sea surface

$$
S(\vec{x}, \omega)=\sum_{i} \nu_{i}^{1 / 3} \frac{e^{-j k_{w} R_{i}}}{R_{i}}+\sum_{i}(-1) \nu_{i}^{1 / 3} \frac{e^{-j k_{w} R_{i}^{\prime}}}{R_{i}^{\prime}},
$$

where $\vec{x}$ is the position of the receiver, $\omega$ is the acoustic frequency, $k_{w}=\omega / c$ is the acoustic wave number in water 
(where $c$ is the sound speed, $1500 \mathrm{~m} / \mathrm{s}$ ), $\nu_{i}$ is the volume of $i$ th airgun element, and $R_{i}$ is the distance from the receiver to the $i$ th airgun element. In the second term, the $(-1)$ indicates the contribution from the virtual "mirror image source" due to the Lloyd's mirror effect of the sea surface (modeled as a pressure release boundary), and $R_{i}^{\prime}$ is the distance from the receiver to the image source of the $i$ th airgun element. Therefore, our airgun array beampattern model includes both the effects of array geometry and the Lloyd's mirror effect caused by sea-surface reflection. Using this model, we calculated the acoustic pressure at a certain radius from the array and normalized it to obtain an estimate of the source beampattern. The airgun elements in this model were treated as monopole sources with a single impulse, while real airgun pulses include a series of bubble pulses (Ziolkowski, 1970). However, the model could still predict the locations of spatial and frequency notches in the airgun array beampattern, since notch locations are mainly determined by the geometric configuration of the array (Parkes and Hatton 1986, Tipler and Llewellyn 2003).

\section{Acoustic ray-tracing model}

In this study, we modeled range-dependent acoustic propagation but considered only reflection from the sea-floor and sea-surface boundaries and refraction due to soundspeed variations. We used the ray-tracing program RAY (Bowlin et al., 1992), which can deal with a range-dependent environment, to calculate sound propagation paths and travel times of the airgun pulses recorded during the modeled CEEs. The fundamental theory underlying RAY is well known; the reader interested in more detail is referred to the relevant literature (e.g., Bowlin et al., 1992; Jensen et al., 1994).

\section{Broadband acoustic propagation modeling}

To model the transient airgun pulse signals recorded on Dtags in the CEEs, we developed a two-dimensional (2D) broadband range-dependent acoustic propagation program based on Fourier synthesis (Jensen et al., 1994). The model, described below, can compute received sound pulses over a specified bandwidth at a single position.

The Fourier pulse synthesis technique is based on the Fourier transform of the continuous wave frequency-domain response multiplied by the spectrum

$$
p(r, z, t)=\frac{1}{2 \pi} \int_{-\omega_{\max }}^{\omega_{\max }} S(\bar{\omega}) H(r, z, \omega) e^{-j \omega t} d \omega,
$$

where $p(r, z, t)$ is the pressure signal of a sound source received at the position $(r, z)$ on a vertical plane, which also includes the source; $r$ is horizontal range; and $z$ is depth. $S(\omega)$ is the source spectrum with a finite bandwidth $2 \omega_{\max }$, and $H(r, z, \omega)$ is the frequency response of a monopole source at a frequency $\omega$. In our program, $H(r, z, \omega)$ is calculated by the existing time-harmonic acoustic model RAM (range-dependent acoustic model), a parabolic equation (PE) model developed by Michael D. Collins at the Naval Research Laboratory in Washington, DC (Collins, 1993). Discretizing the transform Eq. (4), we obtain

$$
\begin{aligned}
\sum_{m=-\infty}^{\infty} p(r, z, k \Delta t+m T) \\
=\frac{\Delta \omega}{2 \pi} \sum_{n=-(N / 2-1)}^{N / 2}[S(\omega) H(r, z, n \Delta \omega) \\
\left.\times e^{-j t_{0} n \Delta \omega}\right] e^{-j(2 \pi n k) / N},
\end{aligned}
$$

where on the right hand side, the frequency within a finite bandwidth is discretized as $N$ samples with values $n \Delta \omega$, with $n=(N / 2-1) \sim N / 2$. On the left-hand side, the time within a finite window $T(=1 / \Delta \omega)$ is sampled at $k \Delta t$, with $k$ $=1,2,3 \ldots \mathrm{N}$. The sampling rate must obey the Nyquist criterion, or aliasing will occur in the frequency domain. Similarly, discretization in the frequency domain can cause wraparound in the time domain if $\Delta \omega$ is too large, with $m$ (on the left-hand side of the equation) being the index of the periodicity of the discretized time-domain signal. To minimize the wrap-around effect while keeping $\Delta \omega$ large enough for reasonable computation time, we applied complex frequency integration (Malick and Frazer, 1987; Jensen et al., 1994). If $N$ is an integer power of two, the fast Fourier transform algorithm is efficient for evaluating the summation.

For all model runs, we placed an artificial absorbing layer in the sediments to prevent sound energy from being reflected or refracted back to the water from the deep bottom. The sound source in our model runs was a bell-shaped single pulse, containing most of its energy in the frequency band from $0 \mathrm{~Hz}$ to three times its central frequency. Mathematically, this pulse can be represented as

$s(t)=0.75-\cos 2 \pi f_{c} t+0.25 \cos 4 \pi f_{c} t, \quad 0 \leqslant t \leqslant T=1 / f_{c}$,

where $f_{c}$ is the center frequency. We used $f_{c}=250 \mathrm{~Hz}$. The model source does not accurately represent the output of an airgun array, but the resulting model output can still predict the arrival time pattern measured at the receiver. Because the low-frequency flow noise is very high in the 2002 Dtag record, and the model source produces $95 \%$ of its energy in the $0-600 \mathrm{~Hz}$ frequency band, we bandpass filtered the 2002 data and model results from 100 to $600 \mathrm{~Hz}$ before comparing them.

\section{RESULTS}

\section{A. 2002 experiment and model results}

Figure 11 shows the wave form and spectrogram of two airgun pulses from the 2002 experiment, recorded on the same whale near the surface (at $24 \mathrm{~m}$ depth) and in deep water (at $420 \mathrm{~m}$ depth). There are three clear arrivals in the pulse recorded at $24 \mathrm{~m}$ depth. The spectrogram shows that the first arrival contains significant high-frequency energy but almost no energy below $250 \mathrm{~Hz}$. In the pulse recorded at $420 \mathrm{~m}$ depth, two strong whale clicks appear at 0.12 and $0.56 \mathrm{~s}$ (reduced arrival time), followed by their echoes. Five arrivals from the airgun pulse also can be seen. The first two weak arrivals at 0.25 and $0.32 \mathrm{~s}$ contain only high frequency 

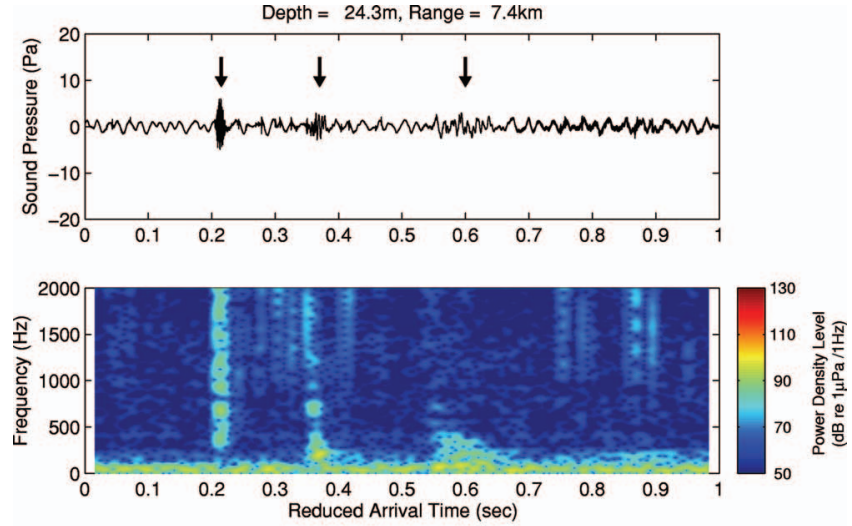

(a)
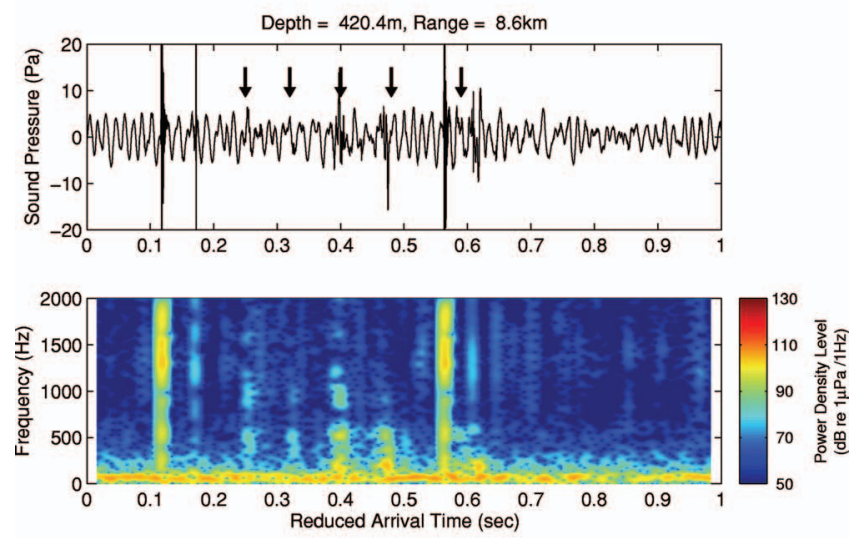

(b)

FIG. 11. The wave form and spectrogram of two airgun pulses recorded on the Dtag when the tagged whale was at (a) $24 \mathrm{~m}$ depth and (b) $420 \mathrm{~m}$ depth during the 2002 experiment. Arrows indicate the airgun arrivals. The intense broadband signals at about $0.12 \mathrm{~s}$ and about $0.56 \mathrm{~s}$ (both followed by their echoes) are clicks produced by the tagged whale.

energy. The last arrival, at $0.6 \mathrm{~s}$, overlaps with the echo of the second whale click. Spectrograms from both depths also show high level, low frequency flow noise.

The first airgun arrivals recorded when the whale was near the surface lacked low-frequency energy because of the high-pass filtering effect of the surface duct (Fig. 7). Figure 12 shows a plot of RAM parabolic equation model output (transmission loss as a function of range and depth for a $600 \mathrm{~Hz}$ source), illustrating the surface ducting effect. Based on our normal mode model runs, we estimated that the cutoff frequency of the surface duct in the 2002 sound speed profile was about $250 \mathrm{~Hz}$, which agrees well with the cutoff frequency shown in the data (Fig. 11). Grating lobes in the airgun array beampattern can also channel energy to nearhorizontal launch angles from the array, and thus into the surface duct. Modeling the beampattern of the Speculator source array at $7 \mathrm{~m}$ depth showed that grating lobes (due to both array geometry and sea-surface reflection) start emerging at $120 \mathrm{~Hz}$, an octave below the duct cutoff frequency. Figure 13 shows examples of the Speculator airgun array beampattern at six frequencies from 50 to $650 \mathrm{~Hz}$. Our beampattern model predicts frequency notches occurring in the downward direction at 107 and $214 \mathrm{~Hz}$, in good agreement with the predicted amplitude spectrum of the on-axis airgun array signature [see Fig. 2(b)]. At $650 \mathrm{~Hz}$, the energy

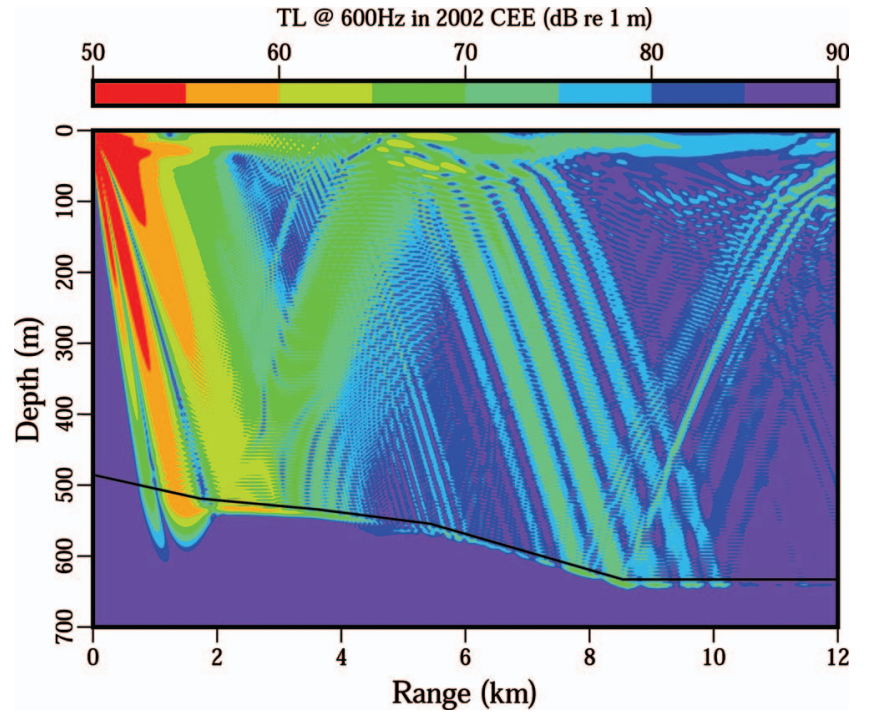

FIG. 12. Transmission loss as a function of range and depth for a $600 \mathrm{~Hz}$ omnidirectional point source at $7 \mathrm{~m}$ depth in the 2002 study environment. The sea floor is indicated by a solid black line.


Launch Angle (degrees)

FIG. 13. The modeled beampattern of the M/V Speculator airgun array at several frequencies, in a vertical plane along the towing direction. Modeled beampattern includes the effects of sea-surface reflection as well as array geometry, as noted in the text. The airgun array was $7 \mathrm{~m}$ below the sea surface for consistency with the modeled source signature (Fig. 2). Launch angles were measured relative to a line extending from bow to stern, and a 3D normalized beampattern was calculated at each frequency. (Because the figure shows 2D beampatterns, the maximum plotted beampattern levels may be less than $0 \mathrm{~dB}$ if the maximum-amplitude lobe of the beampattern occurred outside the plane plotted in this figure.) 


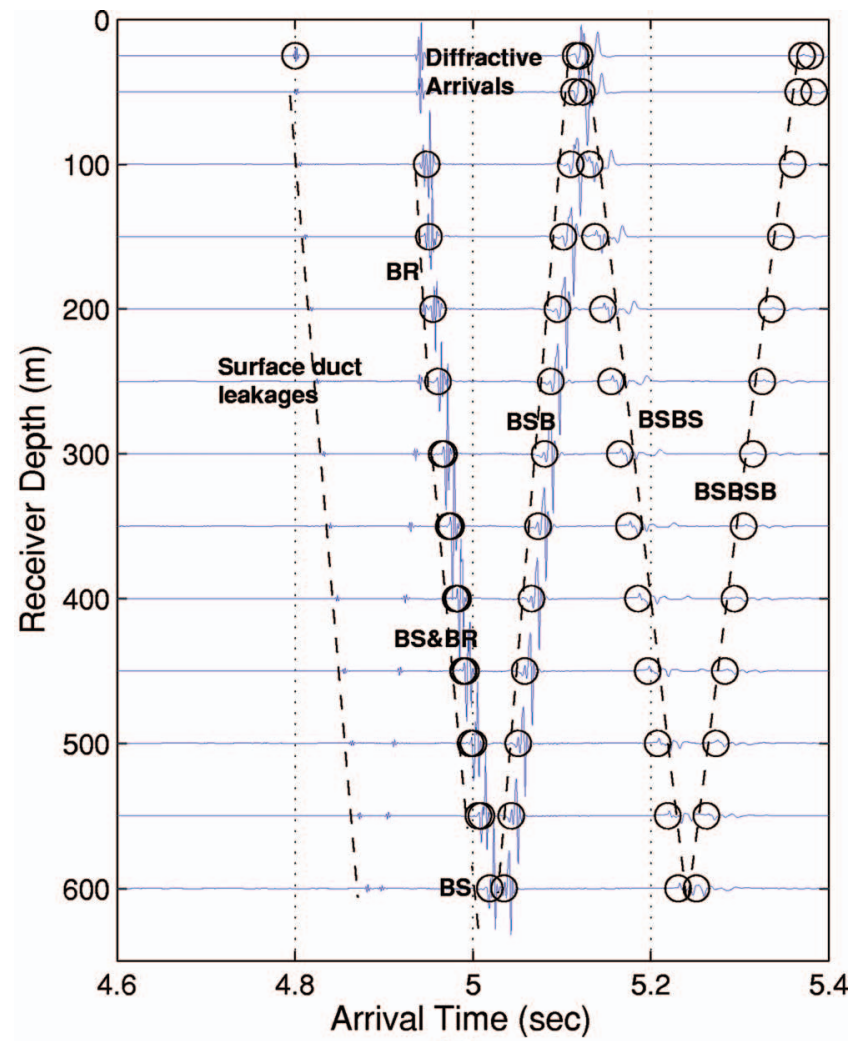

(a)

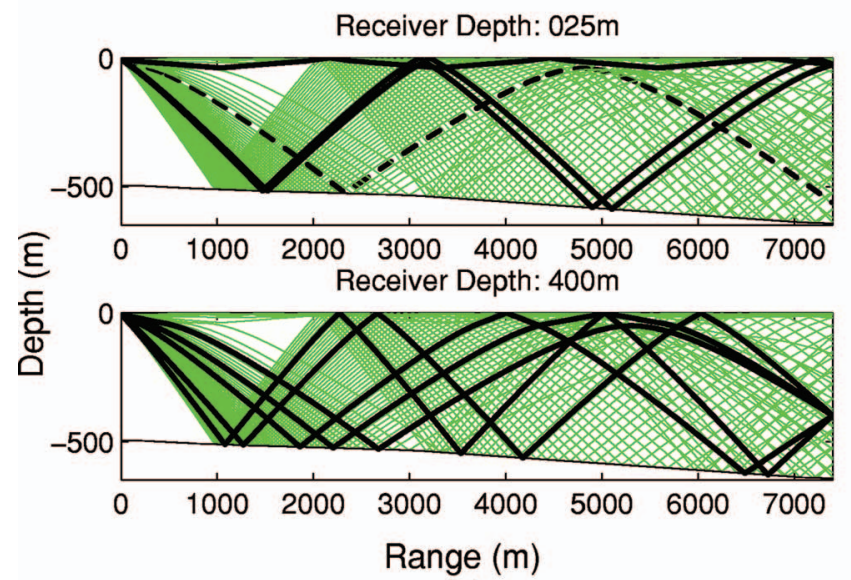

(b)

FIG. 14. (a) Modeled wave forms (blue traces) and eigenray arrival times (highlighted by black circles) at $7.4 \mathrm{~km}$ range and various depths in 2002 . Ray labels are as follows: $\mathrm{B}$ indicates a bottom reflection, $\mathrm{S}$ indicates a surface reflection, and $\mathrm{R}$ indicates refraction in the water column. (b) Modeled eigenray paths (thick black lines) to receivers at $25 \mathrm{~m}$ and $400 \mathrm{~m}$ depth and sound propagation paths (thin green lines) for the 2002 experiment. The dashed line in the $25 \mathrm{~m}$ depth panel is the ultimate BR ray with the shallowest turning point.

emitted by the array at near-horizontal launch angles is even greater than in the downward direction. The model also illustrates that, even at frequencies where the greatest proportion of sound is directed toward the sea floor (e.g., $160 \mathrm{~Hz}$ ), sound carried by the sidelobes (at launch angles closer to the horizontal) is only $20 \mathrm{~dB}$ lower than that in the main, downward-directed lobe [see Fig. 2(b)].

The modeling of the pulse arrivals, including the eigenray arrival time at $7.4 \mathrm{~km}$ range and various depths, is shown in Fig. 14(a). The corresponding ray labels are also included; the labels consist of a "B" for every bottom reflection, an "S" for each reflection at the sea surface, and an "R" to indicate refraction in the water column. For example, a BS ray leaves the source, bounces off the bottom, reflects at the surface, and finally arrives at the receiver, and a BSB ray is like a BS ray with one more bottom bounce before arriving at the receiver. The pulse arrivals calculated from the broadband model arrive exactly when the ray-tracing model predicts, except in the case of the diffractive arrivals near the surface and the surface duct leakages, where ray theory fails (Frisk, 1994). The eigenray paths are also calculated and shown in Fig. 14(b) for two selected depths, 25 and $400 \mathrm{~m}$. The first arrival at the $25 \mathrm{~m}$-depth receiver travels in the surface duct, in concordance with our observation that the first arrival has little low-frequency energy. The BSB and BSBS eigenray paths also produce pulses at the $25 \mathrm{~m}$ receiver depth; however, they arrive almost at the same time and combine into a single pulse. Figure 14(a) also shows that as the receiver goes deeper, the pulses traveling along BSB and BSBS ray paths separate, and the grazing angles of the bottom bounces of these two rays also change. The reflection coefficient contour for 2002 [Fig. 8(b)] shows that the BSBS ray (grazing angle $24^{\circ}$ ) has more bottom loss than the BSB ray (grazing angle of $18^{\circ}$ ), explaining the difference in amplitudes of the BSB and BSBS rays [Figs. 14(a) and 15]. A plot of eigenrays to the $400 \mathrm{~m}$ receiver is shown in Fig. 14(b); as shown in Fig. 14(a), the BR ray path arrives at the receiver almost at the same time as the BS ray. Ray trace output also shows that BR rays can arrive at a receiver at $7.4 \mathrm{~km}$ range only above $560 \mathrm{~m}$ depth. Below that, only BS rays can reach. Conversely, $\mathrm{BR}$ and not $\mathrm{BS}$ rays arrive at receivers at depths shallower than $330 \mathrm{~m}$.

Figure 14(a) also shows surface duct leakage and the diffractive arrivals. Sound energy leaks from the surface duct due to diffraction and scattering at the boundaries of the duct (Weston et al., 1991). Since the propagation model we used does not account for interface roughness at the boundaries of the duct, the leakage seen in our modeling results is due only to diffraction. Sound energy trapped in a surface duct and subject to leakage has been previously described, from a modal sound propagation perspective, as a virtual mode (Labianca, 1972). When such a virtual mode occurs, some surface ducted energy continuously seeps from the duct, but remains trapped in the waveguide as a whole. The leakages eventually return to the duct after bouncing off the bottom or refracting in the water column (Porter and Jensen, 1993). Figure 14(a) shows two arrivals resulting from surface duct leakages; the second of those arrivals actually leaks from the duct first, but undergoes a bottom bounce before arriving at the whale. The broadband PE model also predicts that a receiver in the surface duct will detect diffractive arrivals [Fig. 14(a); Murphy and Davis, 1974]. Unlike the surface duct leakages, diffractive arrivals in the duct are from an upwarddirected ray that is below the duct. As shown in Fig. 14(b), the ray in question is the ultimate BR ray, which has a turning point closer to the base of the surface duct than any other BR ray. The ray turns down at the lower bound of the surface duct (a local maximum in the sound speed profile), and some of its energy enters the duct. 

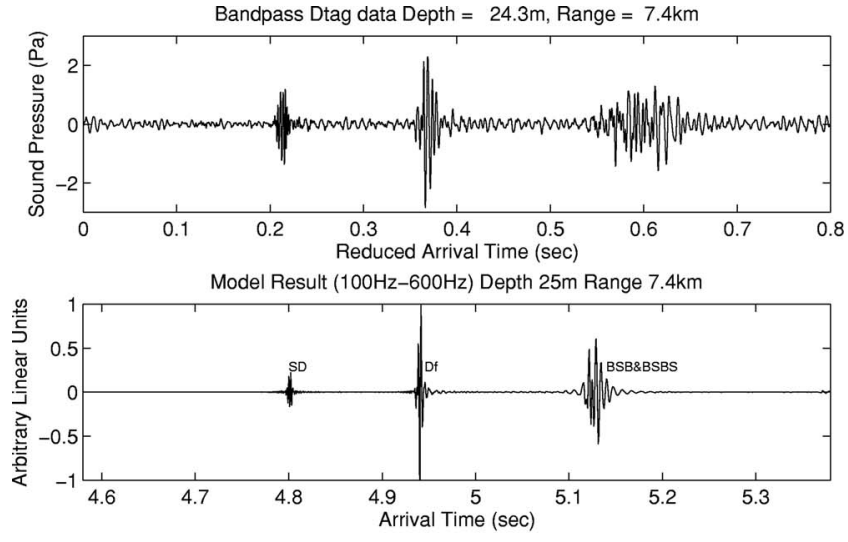

(a)
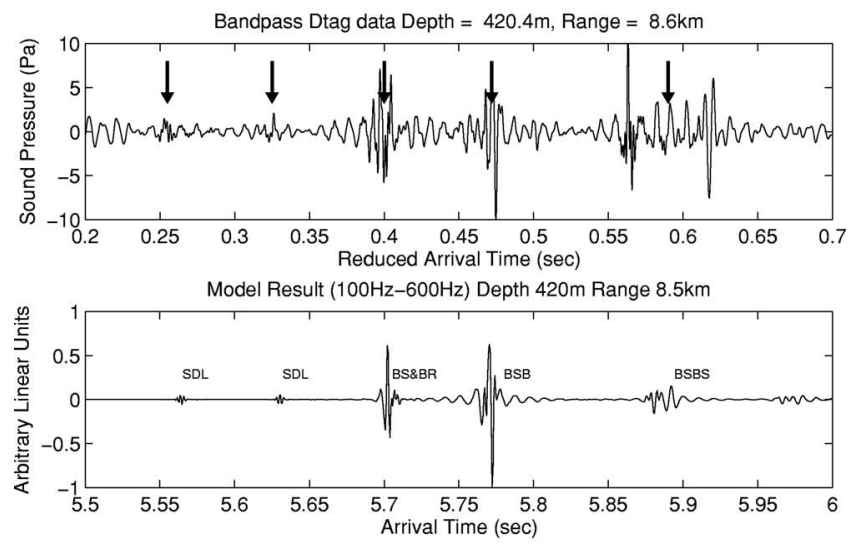

(b)

FIG. 15. Wave form comparison between the 2002 Dtag recordings and broadband model results for a receiver at (a) $7.4 \mathrm{~km}$ range and $24.3 \mathrm{~m}$ depth and (b) $8.5 \mathrm{~km}$ range and $420 \mathrm{~m}$ depth. All wave forms were bandpass filtered between $100-600 \mathrm{~Hz}$, as described in Sec. III. Ray path labels are as follows: B indicates a bottom reflection, $\mathrm{S}$ indicates a surface reflection, SD indicates a surface ducted arrival, SDL indicates a surface duct leakage, and Df indicates diffraction in the water column.

A comparison of wave forms from the Dtag records and the broadband model results is shown in Fig. 15. As shown in Fig. 15(a), the timing and relative amplitudes of modeled arrivals match the data very well for a receiver at $7.4 \mathrm{~km}$ range and $24.3 \mathrm{~m}$ depth. The broadband model also provides very good results compared with the Dtag data at $8.6 \mathrm{~km}$ range and $420 \mathrm{~m}$ depth, where the relative differences between the surface duct leakages and the single bottom bounce pulses are especially well described.

\section{B. 2003 experiment and model results}

Figure 16 shows the wave form and spectrogram of a typical airgun pulse recorded on a tagged whale $11.2 \mathrm{~km}$ from the source at $450 \mathrm{~m}$ depth (the intense broadband signals at about 0.4 and $0.9 \mathrm{~s}$ are clicks produced by the tagged whale). The spectrogram illustrates that, in contrast to the 2002 data, all arrivals from the airgun pulse contain mainly low-frequency energy (below $500 \mathrm{~Hz}$, and concentrated below $200 \mathrm{~Hz}$ ). Because the sound speed profile for the modeled 2003 CEE did not include a significant surface duct, high-frequency sound did not undergo ducted propagation to
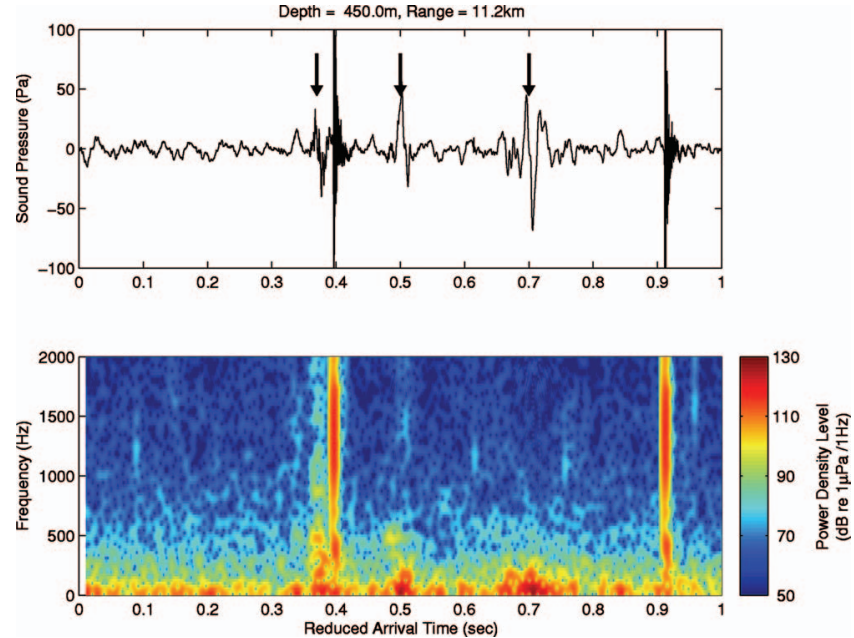

FIG. 16. The wave form and spectrogram of an airgun pulse recorded on the Dtag when the tagged whale was at $450 \mathrm{~m}$ depth and $11.2 \mathrm{~km}$ range during the 2003 experiment. Arrows indicate airgun arrivals. The intense broadband signals at about 0.4 and $0.9 \mathrm{~s}$ are clicks produced by the tagged whale.

the tagged whale near the surface, but rather reached the whale after reflecting from the bottom and the sea surface [see Fig. 17(b)].

The modeled pulse arrivals and eigenray arrival times at $11.2 \mathrm{~km}$ range and various depths are shown in Fig. 17(a). The eigenray paths for receivers at 150 and $450 \mathrm{~m}$ depth are also shown in Fig. 17(b). As they did in the 2002 model runs, the ray and broadband models predicted nearly identical airgun pulse arrival times. The modeled arrival times match fairly well with the data (Figs. 18 and 19). Figure 17(a) shows that the first airgun arrival at $150 \mathrm{~m}$ depth is a BR ray, while that at $450 \mathrm{~m}$ depth is a $\mathrm{BS}$ ray, because no BR rays arrive at receivers below about $200 \mathrm{~m}$ depth at $11.2 \mathrm{~km}$ range. Figure 17 also indicates that the third-arriving rays undergo one more surface reflection than the second-arriving rays, which explains why the third arrivals (shown in Fig. 18) are about $180^{\circ}$ out of phase with the second arrivals (Frisk, 1994).

Figure 19 shows a wave form comparison between the Dtag records and the broadband PE model results for a receiver at $450 \mathrm{~m}$ depth and $11.2 \mathrm{~km}$ range. These model results did not match the data as well as the 2002 model results because our information about bottom characteristics was less precise for the 2003 site, as will be clarified further in the discussion section.

\section{DISCUSSION AND CONCLUSIONS}

Most reviews on the effects of airgun array pulses on marine life have accepted the assumption that airgun noise is limited to low frequencies, and have concentrated on species thought to have good low-frequency hearing (Caldwell, 2002; Popper et al., 2004; Richardson et al., 1995). We found that animals located near the surface when surfaceducting conditions are present may be exposed to measurable levels of airgun sound above $500 \mathrm{~Hz}$. The surface ducting effect described here means that even animals with poor lowfrequency hearing (for example, dolphins and other small odontocetes) could potentially detect and be affected by air- 


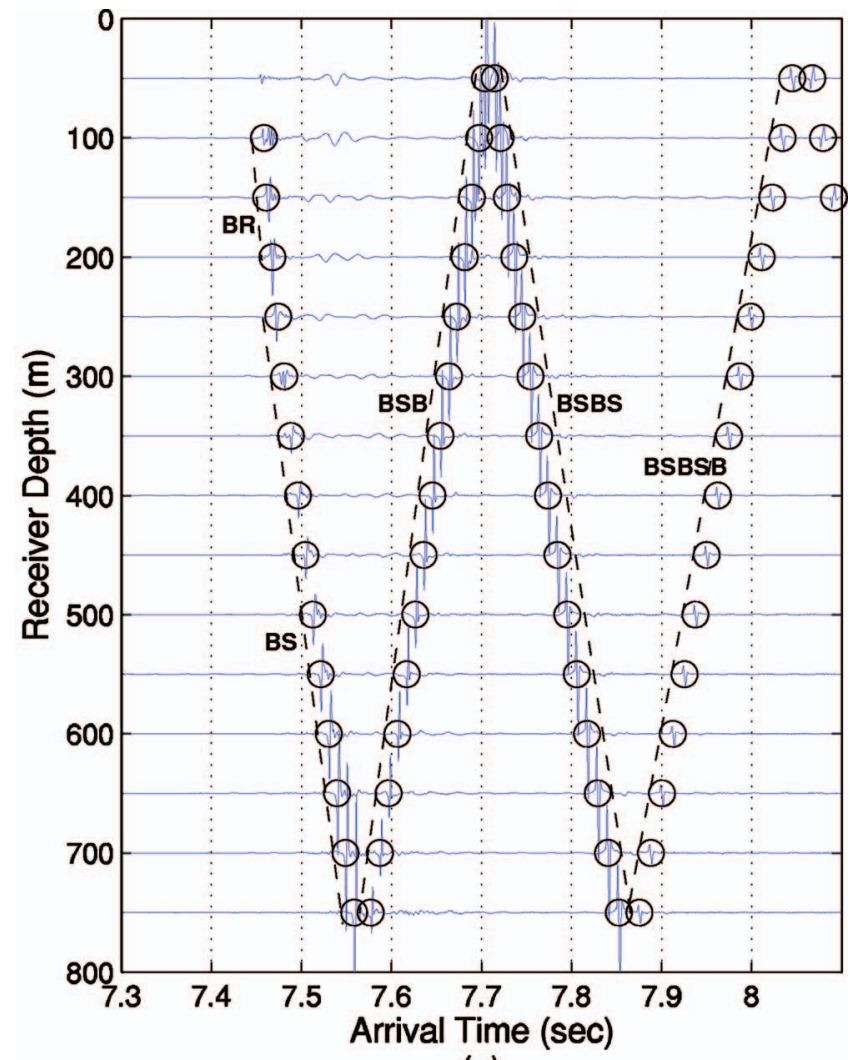

(a)

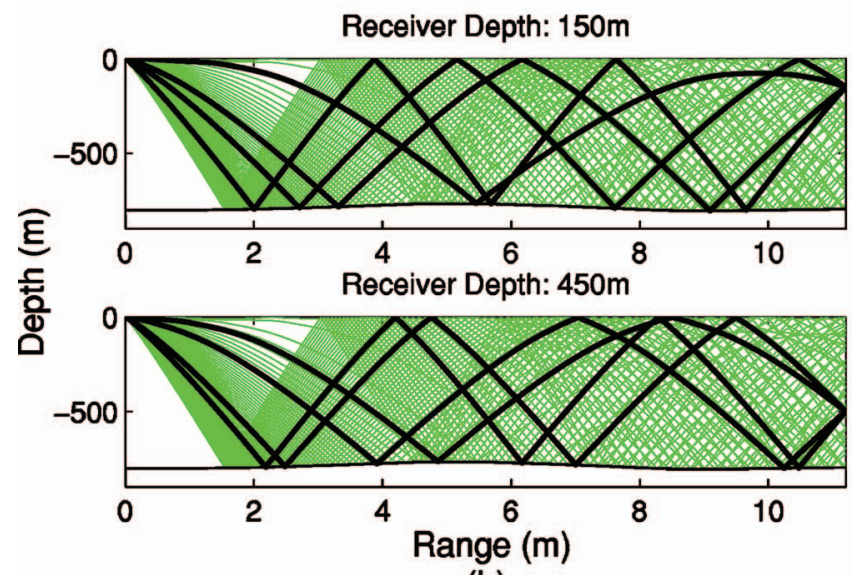

(b)

FIG. 17. (a) Modeled wave forms (blue traces) and eigenray arrival times (highlighted by black circles) at $11.2 \mathrm{~km}$ range and different depths in 2003. Ray path labels are as follows: B indicates a bottom reflection, $\mathrm{S}$ indicates a surface reflection, and $\mathrm{R}$ indicates refraction in the water column. (b) Modeled eigenray paths (thick black lines) to receivers at 150 and $450 \mathrm{~m}$ depth and sound propagation paths (thin green lines) for the 2003 experiment.

gun noise. However, we did not observe the surface ducting effect in all environmental settings, which underscores the influence of temporally and spatially variable oceanographic conditions on acoustic propagation. The received level of airgun pulses clearly depends not only on source-receiver range and on-axis airgun array source level, but also on array beampattern, sound speed profile, bathymetry, and bottom properties.

Our ability to model the absolute intensity of airgun pulses at the whales was limited by incomplete data in a few key areas. First, we did not have an adequate measurement of the source signatures of the airgun arrays (at all launch

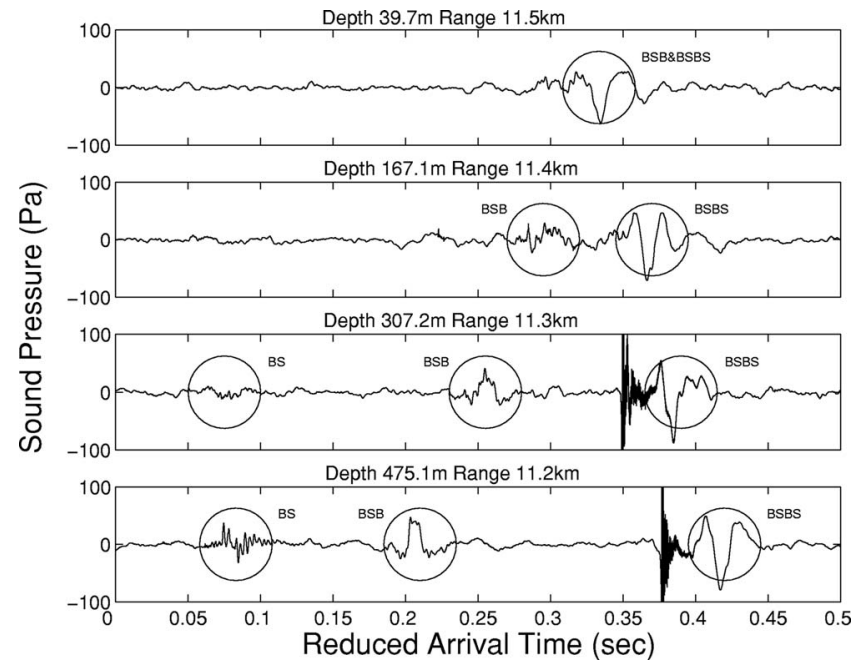

FIG. 18. Wave forms of airgun arrivals recorded on Dtags at different depths and about $11 \mathrm{~km}$ range in 2003. Black circles highlight the time of each airgun arrival. Ray path labels are as follows: B indicates a bottom reflection, and $\mathrm{S}$ indicates a surface reflection.

angles). Also, the lack of suitably detailed information on environmental properties in the 2003 study area explains the mismatch between 2003 model and data wave forms (Fig. 19). First, the 2003 bottom property data was taken about $20 \mathrm{~km}$ from the $2003 \mathrm{CEE}$ site, on the opposite side of the Mississippi Canyon, and errors in bottom parameters result in inaccurate modeling of sound amplitude. Second, in 2003, sound speed data were collected temporally and spatially further from the study area than in 2002. Consequently, inaccuracies in the 2003 sound speed profile resulted in differences between modeled and observed relative arrival times; any errors in bathymetry could also have caused arrival-time discrepancies. Finally, the numerical source used in the models is a point source, which acts like a dipole at low frequencies and emits less energy at launch angles close to the horizontal than does an airgun array. This difference helps explain why airgun arrivals that left the source at near-horizontal launch
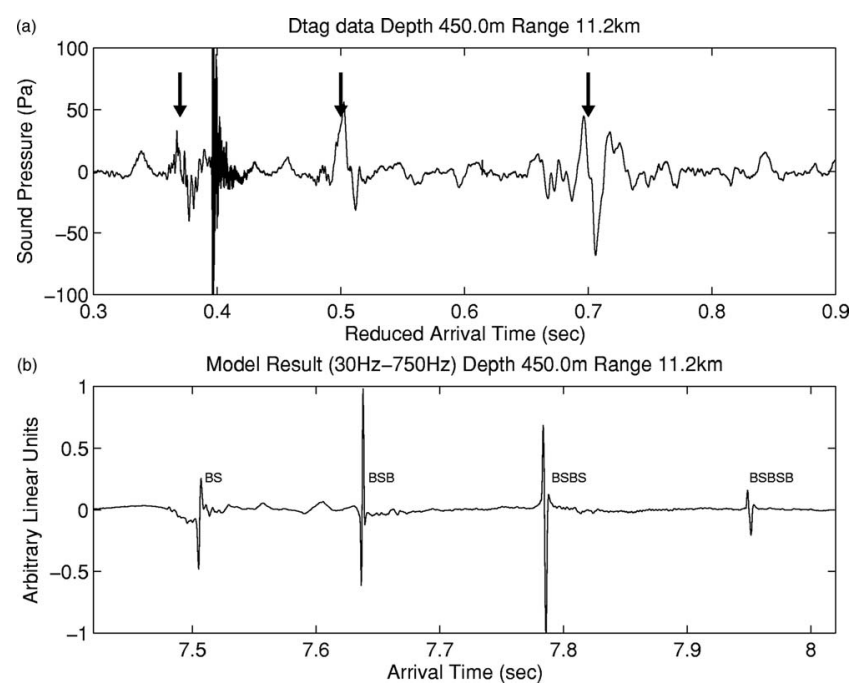

FIG. 19. Wave form comparison between (a) the 2003 Dtag recording and (b) broadband model results for a receiver at $11.2 \mathrm{~km}$ range and $450 \mathrm{~m}$ depth. 
angles have more energy than the model predicts. The observed mismatch between 2003 data and model results emphasizes the fact that accurate modeling of airgun pulse arrivals is impossible without adequate environmental data and source information.

Surface ducted propagation increased the proportion of high-frequency content compared to the seismic (low frequency) content of some airgun arrivals recorded on whales at shallow depths $(<50 \mathrm{~m})$ in 2002 , but not in 2003 , when no surface duct was observed. A reasonable "ducting gain" estimate for the reduction in transmission loss for sound trapped in a surface duct can be obtained by a simple physical argument. The surface duct confines the low-angle trapped energy to its thickness $h$, as opposed to the full water column depth $H$, so that there is an $H / h$ geometric ducting gain for the trapped energy. Also, the ducted energy does not interact with the bottom and suffer bottom loss, so the ducted rays will "gain" the amount of energy they would have lost in bottom interaction if the duct did not exist. Thus we can predicate a "surface duct gain" $G$ in $\mathrm{dB}$ of

$$
G=10 \log (H / h)+\mathrm{TL}(f, r, \theta)
$$

for the portion of the rays trapped in the duct, where TL is the transmission loss for a nonducted ray of source angle $\theta$. Of course, exact model calculations are preferable, and we would recommend that any calculations requiring precision be based on such models.

The exact levels notwithstanding, the data from the 2002-2003 Dtag controlled exposure studies do show that airgun arrays produce significant energy at frequencies well above those actually utilized for geophysical surveys (Caldwell and Dragoset, 2000; see Madsen et al. (2006) for quantification of received levels). Our model results and source beampattern analysis explain why there was more energy in the $500-2500 \mathrm{~Hz}$ frequency band in the airgun signals recorded at a whale near the surface when a surface duct was present.

We recommend that future research should include both modeling and measurement of airgun array source signatures at a full range of angles and at frequencies up to several kilohertz. Collecting (and publishing) accurate and detailed data on airgun array sources would allow for correspondingly accurate and detailed predictions of airgun sound propagation in the ocean. Failure to properly quantify the acoustic source properties of airgun arrays presently limits our ability to predict, test for, and mitigate any potential negative effects they may have. In addition, the ability to predict received levels of airgun pulses as a function of source-receiver range depends on having detailed, current information about the ocean and seabed environment in which the sounds are propagating.

The data we used were collected as part of a controlled exposure experiment designed to study the effect of airgun activity on sperm whale behavior (Miller et al., unpublished). Even assuming behavioral effects can be welldescribed, there are several major obstacles to the interpretation of such controlled exposure data and their integration into policies designed to mitigate adverse effects of airgun sounds on marine life. First, one must quantify received lev- els of airgun noise in a manner that accurately relates to the animals' perception of the sound; ideally, this measured level should be directly proportional to the risk of physical damage or adverse behavioral modifications (Madsen, 2005). Second, most management guidelines for mitigating potential airgun effects on marine mammals define maximum allowable exposure levels and then design regulations to protect animals from exposure to unacceptable sound levels. One popular framework for current discussions on potential effects of human-made sounds on marine species, proposed by Richardson et al. (1995), suggests that a sound source is surrounded by several zones of potential influence on receiving animals: at very close ranges, animals may be injured by a very loud sound; at greater ranges, their behavior or fitness may be affected by the sound; at even greater ranges, they can detect the sound but are not affected by it; and finally, beyond some range, the animals cannot detect the sound at all. While conceptually useful, the model assumes that sound exposure decreases monotonically with range from the source. Accordingly, an allowable exposure level is generally translated to a range from the airgun array within which potentially impacted marine mammals must not occur during airgun operation (Barlow and Gentry, 2004; Richardson et al., 1995). This range is usually estimated from the maximum allowable exposure level using the backcalculated, broadband, on-axis source level of the airgun array. Most allowable range estimates also assume a geometric spreading transmission loss or a range-independent acoustic model with an omnidirectional sound source (Barlow and Gentry, 2004; Gordon et al., 2004). Since most airgun array source levels are calculated only on-axis and for frequencies below $250 \mathrm{~Hz}$ (Gausland, 2000), the range estimation described above does not account for the full frequency range produced by the array or the directionality of the array [although some regulatory approaches include a correction for array beampattern effects (NMFS, 2003)]. Moreover, the detailed aspects of the multipath acoustic propagation, such as the existence of convergence zones and shadow zones, surface ducts, etc., are disregarded.

Our ray trace and PE model results show a convergence zone at $6-8 \mathrm{~km}$ range (2003) or $4-6 \mathrm{~km}$ range (2002) (shown in Fig. 12), which is further confirmed by data on received levels in the Dtag recordings (for details, see Madsen et al., 2006). These results illustrate that in many cases airgun received levels will not decrease monotonically with increasing range, so that a simple spherical or cylindrical spreading law will not accurately predict the observed pattern of received levels. Regulation based on inappropriate application of a geometric spreading law to calculate the extent of exposure zones could result in exposing animals to higher-than-intended noise levels. For example, using a geometric-spreading based calculation method to estimate the range from an airgun array at which a near-surface sperm whale in the Gulf of Mexico would be exposed to a potentially harmful received level of $180 \mathrm{~dB}$ re $1 \mu \mathrm{Pa}$ [root-meansquared (rms)] results in a range of $295 \mathrm{~m}$ (NMFS, 2003). However, received airgun array levels of $180 \mathrm{~dB}$ re $1 \mu \mathrm{Pa}$ (rms) at $18 \mathrm{~m}$ depth in the Gulf of Mexico have been mea- 
sured at ranges up to $\sim 3.5 \mathrm{~km}$ from the source-over ten times the range predicted by the geometric spreading calculation (Tolstoy et al., 2004).

Regulations defining allowable ranges between airgun array sound sources and marine species must take into account the potentially complicated relationship between source-receiver range and depth, acoustic frequency, and received sound level. Other mitigation actions, such as rampup, assume that potentially affected animals will swim away from a source during ramp-up. Our results show, however, that animals may experience increased exposure levels as they swim away from a source under some conditions, and decreased levels as they approach. In this case, an animal seeking to reduce exposure in the short-term may actually approach the source. Source beampattern may also vary dramatically during ramp-up, resulting in variation in received levels and frequency spectra over time at a given location. There is clearly an urgent need better to define the acoustic signatures of airgun arrays and how sound propagates from them. Any efforts to reduce the risk of airguns to marine mammals must include accurate predictions of exposure.

\section{ACKNOWLEDGMENTS}

The authors thank the crews and science parties of the research cruises on which data for this study were collected. Funding for this work was provided by the Office of Naval Research, the U.S. Department of the Interior Minerals Management Service Cooperative Agreements Nos. 1435-01-02CA-85186 and NA87RJ0445, and the Industry Research Funding Coalition. S.L.D.R. was supported by a National Science Foundation Graduate Research Fellowship. Peter Madsen performed airgun pulse extraction, and Peter Madsen and Mark Johnson provided helpful comments on the manuscript. All approaches to animals for tagging were made following the conditions of NMFS research permits 9811578 and 981-1707. The Woods Hole Oceanographic Institution Animal Care and Use Committee approved this research.

Barger, J. E., and Hamblen, W. R. (1980). "The air gun impulsive underwater transducer," J. Acoust. Soc. Am. 68, 1038-1045.

Barlow, J., and Gentry, R. (2004). "Report of the NOAA Workshop on Anthropogenic Sound and Marine Mammals, 19-20 February 2004," NOAA Technical Memorandum NMFS-SWFSC-361.

Blackman, D. K., de Groot-Hedlin, C., Harben, P., Sauter, A., and Orcutt, J. A. (2004). "Testing low/very low frequency acoustic sources for basinwide propagation in the Indian Ocean," J. Acoust. Soc. Am. 116, $2057-$ 2066.

Bowlin, J. B., Spiesberger, J. L., Duda, T. F., and Freitag, L. F. (1992). Ocean Acoustic Ray-Tracing Software RAY, WHOI Technical Report, WHOI-93-10 (Woods Hole Oceanographic Institution, Woods Hole, MA).

Caldwell, J. (2002). "Does air-gun noise harm marine mammals?," The Leading Edge 21, 75-78.

Caldwell, J., and Dragoset, W. (2000). "A brief overview of seismic air-gun arrays," The Leading Edge 19, 898-902.

Clay, C. S., and Medwin, H. (1977). Acoustical Oceanography: Principles and Applications (Wiley, New York).

Collins, M. D. (1993). "A split-step Padé solution for the parabolic equation method," J. Acoust. Soc. Am. 93, 1736-1742.

Dragoset, W. (2000). "Introduction to air guns and air-gun arrays," The Leading Edge 19, 892-897.

Engås, A., Løkkeborg, S., Ona, E., and Soldal, A. V. (1996). "Effects of seismic shooting on local abundance and catch rates of cod (Gadus morhua) and haddock (Melanogrammus aeglefinus)," Can. J. Fish. Aquat.
Sci. 53, 2238-2249.

Frisk, G. V. (1994). Ocean and Seabed Acoustics (P.T.R. Prentice-Hall, Upper Saddle River, NJ).

Gausland, I. (2000). "Impact of seismic surveys on marine life," The Leading Edge 19, 903-905.

Geresi, E., Chapman, N. R., McGee, T., and Woolsey, J. R. (2005). "Gas hydrate geohazard assessment in the northern Gulf of Mexico using a vertical line array," Proceedings of the AAPG Annual Convention, Calgary, Alberta.

Goold, J. C., and Fish, P. J. (1998). "Broadband spectra of seismic survey air-gun emissions, with reference to dolphin auditory thresholds," J. Acoust. Soc. Am. 103, 2177-2184.

Gordon, J., Gillespie, D., Potter, J., Frantzis, A., Simmonds, M. P., Swift, R., and Thompson, D. (2004). "A review of the effects of seismic surveys on marine mammals," Mar. Technol. Soc. J. 37, 16-34.

Hamilton, E. L. (1972). "Compressional-wave attenuation in marine sediments," Geophysics 37, 620-646.

Hamilton, E. L. (1978). "Sound velocity-density relations in sea-floor sediments and rocks," J. Acoust. Soc. Am. 63, 366-377.

Hamilton, E. L. (1980). "Geoacoustic modeling of the sea floor," J. Acoust. Soc. Am. 68, 1313-1340.

Jensen, F. B., Kuperman, W. A., Porter, M. B., and Schmidt, H. (1994). Computational Ocean Acoustics (AIP, Woodbury, NY).

Jochens, A. E., and Biggs, D. C. (2003). Sperm Whale Seismic Study in the Gulf of Mexico, Annual Report: Year 1 (U.S. Department of the Interior Minerals, Management Service, Gulf of Mexico OCS Region, New Orleans, LA).

Jochens, A. E., and Biggs, D. C. (2004). Sperm Whale Seismic Study in the Gulf of Mexico, Annual Report: Year 2 (U.S. Department of the Interior Minerals, Management Service, Gulf of Mexico OCS Region, New Orleans, LA).

Johnson, M. P., and Tyack, P. L. (2003). "A digital acoustic recording tag for measuring the response of wild marine mammals to sound," IEEE J. Ocean. Eng. 28, 3-12.

Jovanovich, D. B., Sumner, R. D., and Akins-Easterlin, S. L. (1983). "Ghosting and marine signature deconvolution: a prerequisite for detailed seismic interpretation," Geophysics 48, 1468-1485.

Labianca, F. M. (1972). "Normal modes, virtual modes, and alternative representations in the theory of surface-duct sound propagation," J. Acoust. Soc. Am. 53, 1137-1147.

Laws, R., Landrø, M., and Amundsen, L. (1998). “An experimental comparison of three direct methods of marine source signature estimation," Geophys. Prospect. 46, 353-389.

Madsen, P. T. (2005). "Marine mammals and noise: Problems with root mean square sound pressure levels for transients," J. Acoust. Soc. Am. 117, 3952-3957.

Madsen, P. T., Johnson, M., Miller, P. J. O., Aguilar de Soto, N., Lynch, J., and Tyack, P. L. (2006). "Quantitative measures of air gun pulses recorded on sperm whales (Physeter macrocephalus) using acoustic tags during controlled exposure experiments,'J. Acoust. Soc. Am. 120, 2366-2379

Mallick, S., and Frazer, L. N. (1987). "Practical aspects of reflectivity modeling," Geophysics 52, 1355-1364.

McCauley, R. D., Fewtrell, J., and Popper, A. N. (2003). "High intensity anthropogenic sound damages fish ears," J. Acoust. Soc. Am. 113, 638642 .

McGee, T., Geresi, E., Lutken, C., Woolsey, B., Higley, P., and Sharpe, S. (2003). Operation Report: The 8-14 October, 2003, Cruise of the R/V PELICAN, to deploy the CMRET vertical line array in Mississippi Canyon 798 and Atwater Valley 14, northern Gulf of Mexico, MMRI/CMRET, University of Mississippi.

Miller, P. J. O., Johnson, M. P., Madsen, P. T., Quero, M. E., Biassoni, N., King, R., and Tyack, P. L. (unpublished). "At-sea experiments provide preliminary evidence that airguns affect the foraging behavior of sperm whales in the Gulf of Mexico."

Murphy, E. L., and Davis, J. A. (1974). "Modified ray theory for bounded media," J. Acoust. Soc. Am. 56, 1747-1760.

National Marine Fisheries Service (NMFS) (2003). "Taking and importing marine mammals; Taking marine mammals incidental to conducting oil and gas exploration activities in the Gulf of Mexico," Federal Register 68, 9991-9996.

Nieukirk, S. L., Stafford, K. M., Mellinger, D. K., Dziak, R. P., and Fox, C. G. (2004). "Low-frequency whale and seismic airgun sounds recorded in the mid-Atlantic Ocean," J. Acoust. Soc. Am. 115, 1832-1843. 
Parkes, G., and Hatton, L. (1986). The Marine Seismic Source (D. Reidel, Dordrecht, Holland).

Popper, A. N., Fewtrell, J., Smith, M. E., and McCauley, R. D. (2004), "Anthropogenic sound: Effects on the behavior and physiology of fishes," Mar. Technol. Soc. J. 37, 35-40.

Porter, M. B. (1995). The KRAKEN Normal Mode Program (SACLANT Undersea Research Center, La Spezia, Italy).

Porter, M. B., and Jensen, F. B. (1993). "Anomalous parabolic equation results for propagation in leaky surface ducts," J. Acoust. Soc. Am. 94, $1510-1516$.

Richardson, W. J., Greene, Jr., C. R., Malme, C. I., and Thompson, D. H. (1995). Marine Mammals and Noise (Academic, San Diego, CA).

Schmidt, H. (2004). OASES version 3.1 User Guide and Reference Manual; http://acoustics.mit.edu/faculty/henrik/oases.html. Last accessed 10/30/ 2006.

Tipler, P. A., and Llewellyn, R. (2003). Modern Physics (W.H. Freeman and Company, New York).

Tolstoy, M., Diebold, J. B., Webb, S. C., Bohnenstiehl, D. R., Chapp, E., Holmes, R. C., and Rawson, M. (2004). "Broadband calibration of R/V Ewing seismic sources," Geophys. Res. Lett. 31, L14310.
Turgut, A., McCord, M., Newcomb, J., and Fisher, R. (2002). "Chirp sonar sediment characterization at the northern Gulf of Mexico Littoral Acoustic Demonstration Center experimental site," Oceans '02 MTS/IEEE 4, 22482252.

Urick, R. J. (1975). Principles of Underwater Sound for Engineers (McGraw-Hill, New York).

Weston, D. E., Esmond, C. G., and Ferris, A. (1991). "The duct leakage relation for the surface sound channel," J. Acoust. Soc. Am. 89, 156-164. Zimmer, W. M. X., Tyack, P. L., Johnson, M. P., and Madsen, P. T. (2005). "Three-dimensional beam pattern of regular sperm whale clicks confirms bent-horn hypothesis,” J. Acoust. Soc. Am. 117, 1473-1485.

Ziolkowski, A. (1970). "A method for calculating the output pressure waveform from an air gun," Geophys. J. R. Astron. Soc. 21, 137-161.

Ziolkowski, A., Parkes, G., Hatton, L., and Haugland, T. (1982). "The signature of an airgun array: Computation from near-field measurements including interactions," Geophysics 47, 1413-1421.

Ziolkowski, A., and Johnston, R. G. K. (1997). "Marine seismic sources: QC of wavefield computation from near-field pressure measurements," Geophys. Prospect. 45, 611-639. 